\title{
Chemical Functionalization of Carbon Nanotubes with Polymers: A Brief Overview
}

\author{
Ana Maria Díez-Pascual
}

Citation: Díez-Pascual, A.M.

Chemical Functionalization of Carbon Nanotubes with Polymers: A Brief Overview. Macromol 2021, 1, 64-83. https://doi.org/10.3390/macromol 1020006

Academic Editor: Dimitrios Bikiaris

Received: 6 February 2021

Accepted: 18 March 2021

Published: 30 March 2021

Publisher's Note: MDPI stays neutral with regard to jurisdictional claims in published maps and institutional affiliations.

Copyright: (C) 2021 by the author. Licensee MDPI, Basel, Switzerland. This article is an open access article distributed under the terms and conditions of the Creative Commons Attribution (CC BY) license (https:// creativecommons.org/licenses/by/ $4.0 /)$
Universidad de Alcalá, Facultad de Ciencias, Departamento de Química Analítica, Química Física e Ingeniería Química, Ctra. Madrid-Barcelona Km. 33.6, 28805 Alcalá de Henares, Madrid, España (Spain); am.diez@uah.es; Tel.: +34-918-856-430

\begin{abstract}
Carbon nanotubes (CNTs), the one-dimensional allotropes of carbon, have attracted noteworthy research interest since their discovery in 1991 owing to their large aspect ratio, low mass density, and unique chemical, physical, and electronic properties that provide exciting possibilities for nanoscale applications. Nonetheless, two major issues should be considered when working with this sort of nanomaterial: their strong agglomerating tendency, since they are typically present as bundles or ropes of nanotubes, and the metallic impurities and carbonaceous fragments that go along with the CNTs. The successful utilization of CNTs in a wide variety of applications-in particular, in the field of polymer composites-depends on their uniform dispersion and the development of a strong chemical interaction with the polymeric matrix. To achieve these aims, chemical functionalization of their sidewalls and tips is required. In this article, a brief overview of the different approaches for CNT modification using polymers is provided, focusing on the covalent functionalization via "grafting to" or "grafting from" strategies. The characteristics and advantages of each approach are thoroughly discussed, including a few typical and recent examples. Moreover, applications of polymer-grafted CNTs as biosensors, membranes, energy storage substances, and EMI shielding are briefly described. Finally, future viewpoints in this vibrant research area are proposed.
\end{abstract}

Keywords: carbon nanotubes; polymers; nanocomposites; functionalization approaches

\section{Introduction}

Carbon nanotubes (CNTs) are 1D carbon-based nanomaterials discovered by Iijima in 1991, which present high length to diameter ratio (>1000), great flexibility, low density $\left(\sim 1.9 \mathrm{~g} / \mathrm{cm}^{3}\right)$ and outstanding electrical mechanical, and thermal characteristics [1,2], hence being ideal candidates for a wide range of applications including the development of multifunctional nanocomposites [3]. Their superior elastic modulus (up to $1 \mathrm{TPa}$ ) and strength (up to $300 \mathrm{GPa}$ ) place them amongst the strongest materials ever known, hence being perfect as reinforcements for polymers [4,5]. Three key kinds of CNTs have been reported: (1) those containing of a single graphite sheet rolled up like a cylinder, with diameter in the range of $0.5-3 \mathrm{~nm}$, named as single-walled carbon nanotubes (SWCNTs, Figure 1A,B). (2) those with a double-layer structure containing two sheets of graphene folded upon each other, with diameters typically ranging between 1 and $4 \mathrm{~nm}$, named as double-walled carbon nanotubes (DWCNTs). (3) those comprising concentric cylinders (several SWCNTs), with diameters in the range of 3-40 nm, named as multiwalled carbon nanotubes (MWCNTs, Figure 1C,D)). These two kinds of CNTs can be synthesized via diverse ways [6], namely chemical vapour deposition (CVD) from hydrocarbons, arcdischarge and laser ablation processes. Arc-discharge and laser ablation were the original techniques to prepare SWCNTs at a large scale. They include the condensation of vapour carbon atoms arising from the vaporization of solid carbon [7]. In the arc-discharge process, a metal catalyst is required, resulting in metallic impurities, while the key subproducts of the reactions occurring at high temperature are carbon-based impurities. The laser process produces crystalline CNTs of the best quality with low defect content and high length to 
diameter ratio in comparison to the other synthesis approaches [8], whereas CNTs prepared via CVD have many defects since the growth is performed at a temperature. The final properties of CNT-reinforced composites are strongly influenced by the length to diameter ratio, quality, nature and impurity content, thus the CNT source.

(A)
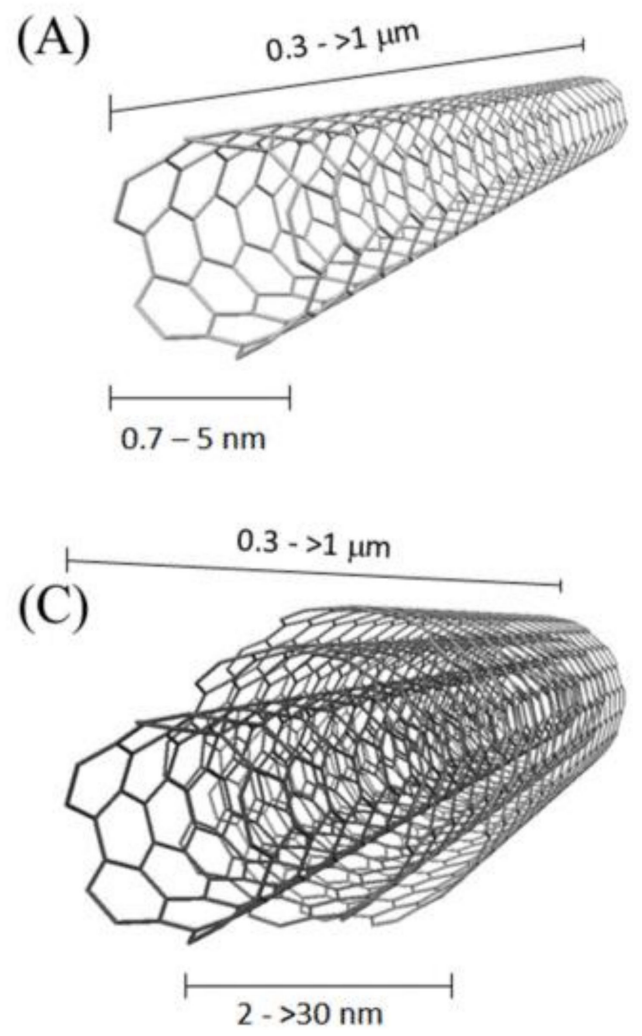
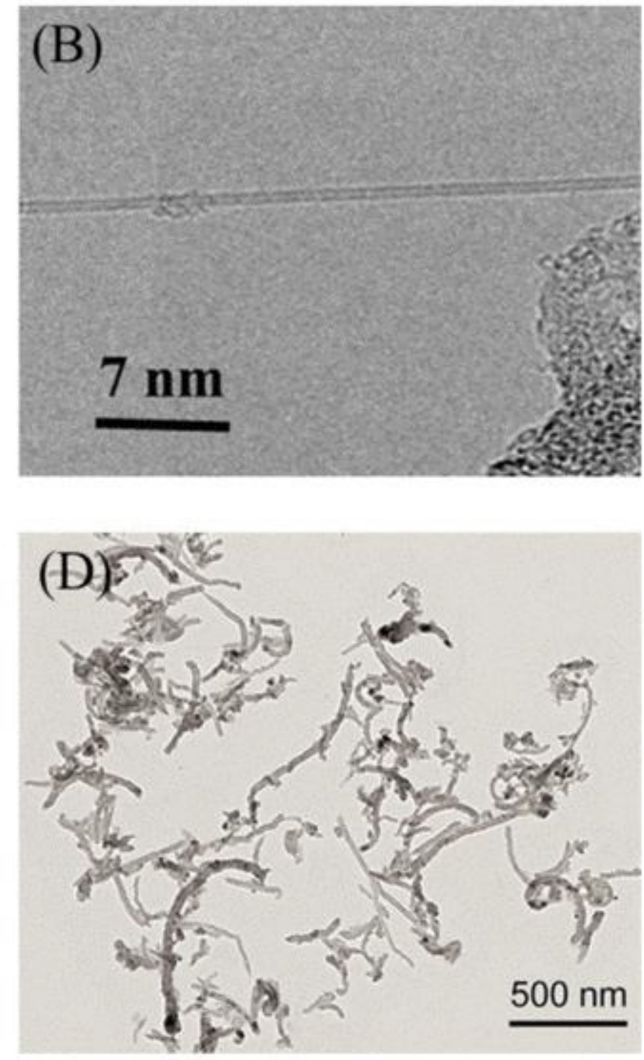

Figure 1. Representation of the structure of a single-walled carbon nanotube (SWCNT) (A) and a multiwalled carbon nanotube (MWCNT) (C) and their typical transmission electron micrographs (B,D). Adapted from [7].

However, obtaining pure monodisperse SWCNTs in large quantities is still a challenge. In this regard, two important issues must be addressed when dealing with this sort of nanomaterials. On the one hand, the high agglomerating trend of CNTs, especially SWCNTs, that commonly appear as bundles or ropes of nanotubes. On the other hand, the catalyst (in the form of metallic nanoparticles) and the carbon-based impurities accompanying the CNTs diminish their purity, and these impurities strictly lessen their properties, in particular the mechanical and electrical. The raw CNTs soot comprises a lot of impurities. Thus, extensive research has been dedicated to the purification of CNTs in order to remove extraneous nanoparticles that alter the CNT physicochemical characteristics. The purification method most widely employed consists in the CNT oxidation with strong acids [9] like perchloric, hydrochloric, nitric, sulfuric or a mixture of them. However, this tactic [10] brings defects into their cylindrical structure that can have an adversative outcome on their mechanical characteristics and/or disturb the electronic pi cloud, dropping their conductivity, and can induce important harm such as tube fracture or sidewall opening. The successful exploitation of CNTs in the field of composites requires their uniform distribution all over the matrix. Extra dare is to attain a good interfacial adhesion between the nanotube and the matrix, which is reflected in an effective load transfer, a pre-requisite to obtain materials with enhanced mechanical properties [11]. Comprehensive review articles on the purification of CNTs can be found elsewhere $[12,13]$. 
Taking into account the aforementioned issues, several methods have been reported such as mechanical dispersion (i.e., ultrasonication [14], ball-milling [15], plasma treatment [16]) and chemical modification comprising either non-covalent or covalent bonding between nanotubes and polymers (Scheme 1, [17]).

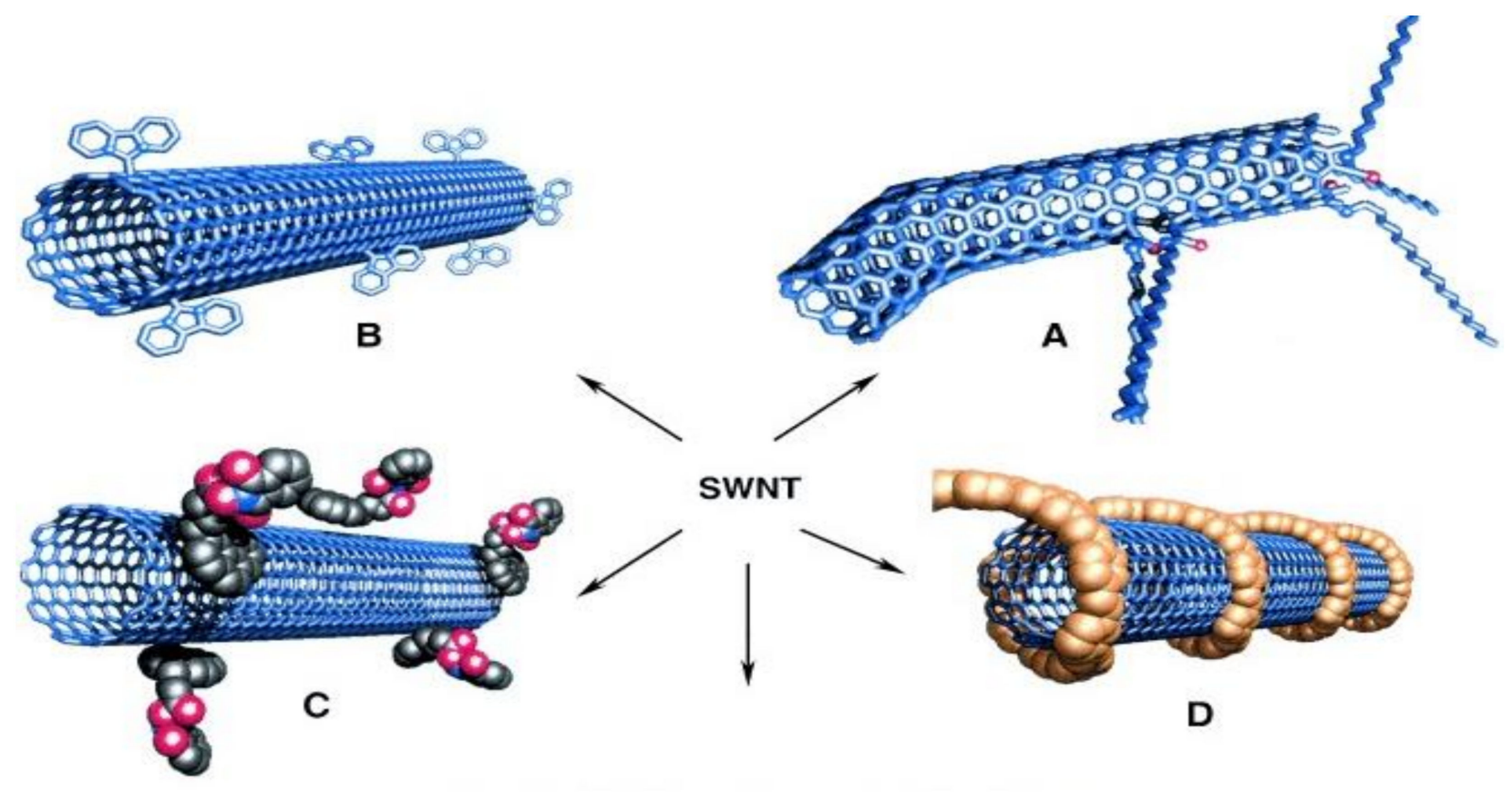

Scheme 1. Schematic representation of the CNT functionalization routes using polymers: covalent functionalization at the CNT sidewalls (A) or defects (B) and non-covalent functionalization via $\pi-\pi$ stacking interactions (C) or wrapping (D). Adapted from [17], with permission from Wiley-VCH.

The non-covalent method consists in the physical adsorption and/or wrapping of polymers to the CNT surface. The walls of the CNTs are able to interact with polymers by means of $\pi-\pi$ stacking interactions as well as with those comprising heteroatoms with free electron pairs. This path does not spoil the aromatic system of the CNTs, thus maintains their structure and properties. The covalent approach entails the "grafting" (chemical anchoring) of polymeric segments to CNTs, and can be implemented via "grafting to" or "grafting from" tactics. It is based on the preparation of a modified polymer able of reacting with the edges or sidewall of as-produced or functionalized (i.e., acid-treated, amine-functionalized, etc.) CNTs [18]. Though, the functionalization reactions in the presence of acids normally cut the CNTs and can cause substantial destruction on their surface or even inducing unrolling [19]. The incorporation of defects in their tube-shaped structure can negatively influence their physicochemical characteristics. Another drawback of this approach is that the amount of polymer grafted to the CNTs is limited due to the poor reactivity and elevated steric barrier of the polymeric segments.

In the "grafting from" route the polymer is developed from the surface of the nanotubes by in situ polymerization of monomers started by molecules placed on the edges and sidewalls of the tubes. The great reactivity of monomers makes this approach effective and manageable, allowing the development of nanocompounds with good grafting level. Though, this technique needs rigorous monitor of the quantities of each reagent and the polymerization requirements. Otherwise, CNT functionalization can be carried out via plasma treatment [16], a time sparing and non-toxic procedure for modifying CNTs via directly creating an elevated amount of functional groups. The degree of hydrophilicity of the CNT surface can easily be converted via plasma treating, thus enabling the dispersion within the polymer matrix [20]. Moreover, this approach does not modify the inherent CNT physical characteristics. 
In this review, several tactics for CNT modification with polymers will be exemplified, focusing particularly on the covalent functionalization via "grafting to" and "grafting from" strategies, and the advantages of each procedure will be discussed. Taking into account the vast number of papers reported on this issue, it is not feasible to cover all the aspects related to this topic in the present review. Consequently, only the most representative and significant examples published up to date will be described. The goal is to provide the reader a concise and useful description about the key functionalization strategies developed in the field and their potential applications. For a comprehensive review on the topic, please refer to elsewhere [21-26]. Finally, future viewpoints in this vibrant research area will be provided.

\section{Covalent Route for CNT Functionalization}

When a covalent modification occurs, carbon atoms change from $\mathrm{sp}^{2}$ to $\mathrm{sp}^{3}$ hybridization. One way is the CNT oxidation at high temperature using air; this results in the unrolling of end caps. They can also be oxidized using different acids and their combinations, including $\mathrm{H}_{2} \mathrm{SO}_{4}+\mathrm{HNO}_{3}+\mathrm{HCl}, \mathrm{H}_{2} \mathrm{SO}_{4}+\mathrm{HNO}_{3}, \mathrm{HNO}_{3}+\mathrm{HCl}$, etc. [23]. The oxidation of CNTs may originate ketone, carboxyl, hydroxyl, carbonyl, and epoxy groups on the CNT surface that improve their interaction with polymers. Nonetheless, chemical functionalization may decrease the length-to-diameter ratio and modify the electronic structure of the carbon nanotube, resulting in an enhancement of $\mathrm{sp}^{3}$ hybridization, hence a band gap widening, and thus reducing their conductivity.

As indicated earlier, the functionalization of CNTs with polymers can be separated into two groups: noncovalent or covalent linking of polymer chains to nanotubes. In the second method, CNTs are functionalized by irreversible linking of polymers either to their sidewall (sidewall functionalization) or at defect points (defect functionalization) typically located at the borders (Scheme 1) and can be carried out via "grafting to" or "grafting from" approaches (Scheme 2).

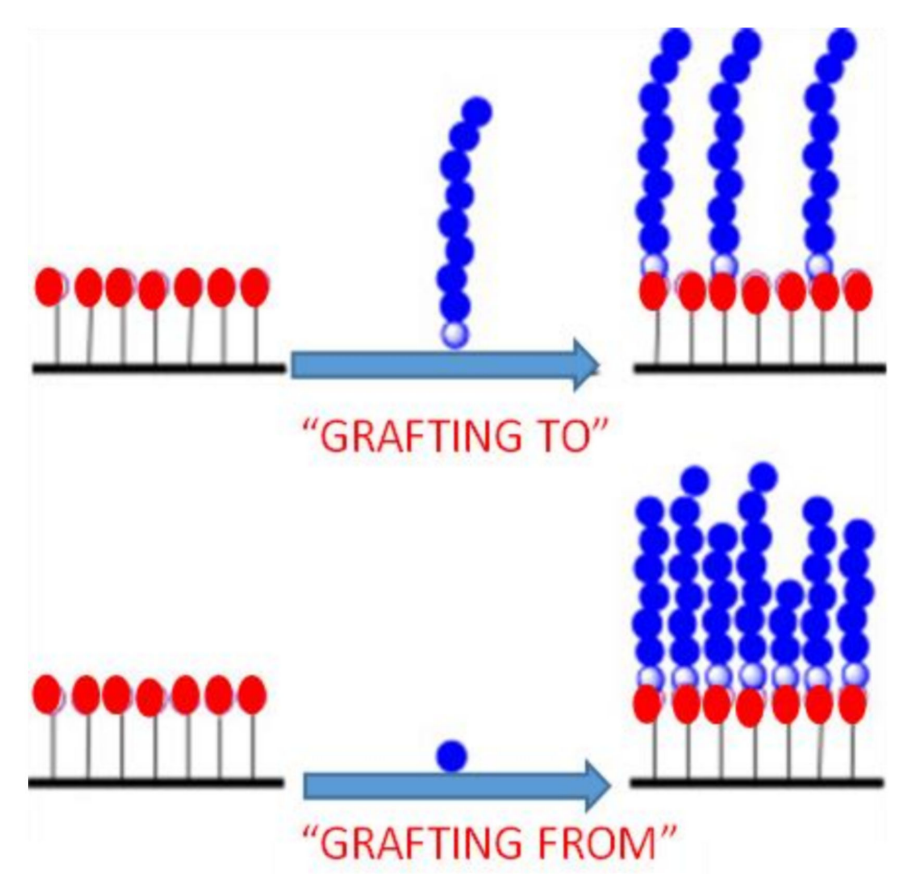

Scheme 2. Pictorial representation of the "grafting to" and "grafting from" approaches. Red spheres indicate CNT binding sites, a single blue sphere represents a monomer, and many blue spheres denote the polymer. 
The functionalization of CNTs makes them soluble in numerous solvents. CNTs have only partial solubility in several solvents. Nonetheless, attaching with polymers allows them to be dispersed in many more solvents. Solubility in water imparts them certain uses in the biomedical arena, particularly in biosensors and drug delivery [24]. Grafting is carried out to improve the polymer-nanotube interfacial adhesion, which typically leads to a CNT disentanglement and debundling. The exfoliation of CNTs leads to enhanced solubility; strong adhesion would result in effective CNT-matrix load transfer, hence improved mechanical properties of the composites. Many physicochemical, biological, and EMI shielding properties of nanocompounds with CNTs grafted to polymers are improved compared to the raw components.

\section{1. "Grafting To" Strategy}

This method usually requires formerly prepared polymer chains that react with either as-produced, oxidized, or functionalized CNTs. Typically, additions to the CNT double bonds (i.e., radical, carbanion, cycloaddition reactions, etc.) are used [25], provided that their bending makes them sensitive to a variety of addition reactions. Otherwise, defect points including open edges of oxidized CNTs with terminal COOH groups permit covalent anchoring of segments or oligomers [26]. Frequently, hydroxyl or amino-terminated polymers are attached via esterification anhydridation or amidation reactions, respectively, with the $\mathrm{COOH}$ groups of the nanotube surface. A benefit of this technique is that preformed commercial polymers with a known mass can be used. The major problem of the procedure is that it yields only a few grafting linkages [27]. It is restricted to polymers encompassing highly reactive groups. In the following sections, some representative examples on "grafting to" reactions described up to date in the literature will be presented.

\subsubsection{Coupling and Nucleophilic Addition Reactions}

Over the last two decades, numerous investigations have focused on coupling and nucleophilic addition reactions between polymers and modified nanotubes. For instance, Xie et al. [28] functionalized SWCNTs with phenylalkyne groups by means of diazonium salt reactions; subsequently, these reacted with copolymers synthesized via free radical polymerization: benzyl chlorinated polystyrene-co-poly(pchloromethylstyrene) and polystyrene-co-poly(p-chloromethylstyrene)-b-polystyrene. Under mild conditions, $\mathrm{Pd}$ was used as a catalyst to connect the alkyne-modified SWCNTs with the benzyl chloride groups, resulting in a grafting extent of 53 and $81 \mathrm{wt} \%$, respectively. Similarly, You et al. [29] attached thiol-reactive moieties onto MWCNT sidewalls, which reacted with a thiol-terminated poly[N-(2-hydroxypropyl)methacrylamide] (PHPMA) via a coupling reaction under mild conditions. This coupling approach is successful for the synthesis of polymer-modified MWCNTs soluble in aqueous media. Liu and coworkers [30] used tert-butyllithium and ferrocene to perform a direct monolithiation onto oxidized MWCNTs resulting in p-chloromethylstyrene-terminated MWCNTs. Afterward, the modified CNTs were functionalized with polystyryllithium, and thermogravimetric analysis indicated a grafting extent of $80 \mathrm{wt} \%$.

Zhang and coworkers [31] carried out a thiol-ene addition reaction between (3-mercaptopropyl)trimethoxysilane and vinyl-terminated low-density polyethylene (LDPE) and trimethoxysilane-functionalized MWCNTs under mild reaction conditions. This resulted in an efficient reaction with a high grafting degree (18 wt \%). In addition, the authors provided the evidence that end-grafted LDPE chains, which are clearly observed in TEM images (Figure 2), can render high compatibility and good CNT-matrix interfacial interactions, and thus promote homogeneous dispersion. 


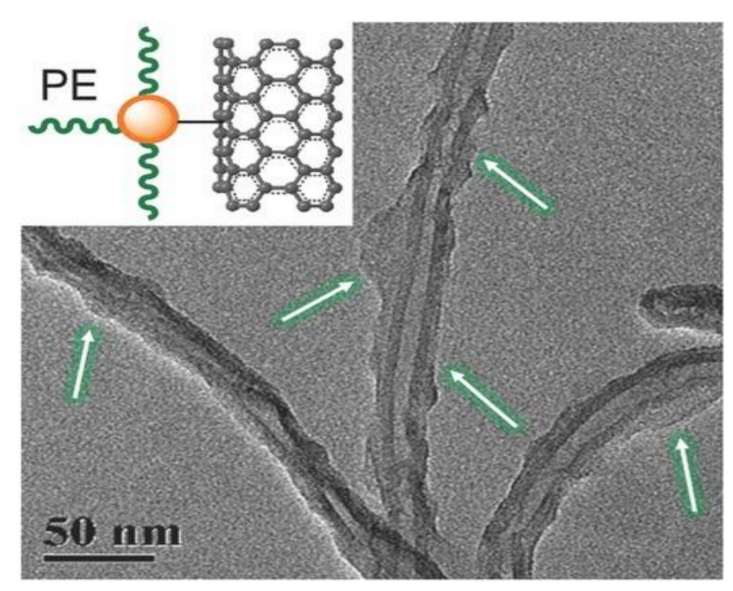

Figure 2. TEM images showing the low-density polyethylene (LDPE) chains grafted onto the MWCNTs. The inset shows a depiction of the polymer grafting. Taken from [31], with permission from Wiley-VCH.

An effective path for CNT functionalization is via an organometallic approach. It has been reported that epoxy groups can be attached onto the CNT surface of CNTs through a one-pot process including two stages [32]. The former is the nucleophilic addition of an organolithium reactive to the aromatic rings of the CNTs leading to the formation of CNT carbanions. The other is the nucleophilic substitution with halogen or hydroxyl oxacylcopropanes, such as epichlorohydrin, and comprises the reaction between the nanotube carbanions and the carbon atom linked to the chlorine, with the subsequent removal of lithium chlorine. The epoxy group may be transformed into other functionalities via a ring-opening method, which allows anchoring to hydroxyl or amine-modified polymers. Following this methodology, an aminated polyphenylene sulphide $\left(\mathrm{PPS}-\mathrm{NH}_{2}\right)$ derivative was been grafted to epoxy-functionalized SWCNTs [33]. A solution of n-butyllithium was added to a SWCNT suspension in toluene (Scheme 3). Then, epichlorohydrin was added and the mixture (SWCNT-EP) was stirred and centrifuged. PPS- $\mathrm{NH}_{2}$ was suspended in ethanol and both polymer and SWCNT-EP dispersions were mixed and refluxed at $140{ }^{\circ} \mathrm{C}$ for $4 \mathrm{~h}$ under nitrogen atmosphere. The resulting product (SWCNT-EP/PPS- $\mathrm{NH}_{2}$ ) was vacuum dried, and the degree of grafting was close to $25 \%$. Wu and coworkers [34] carried out the reaction between acyl-chloride-modified MWCNTs and polystyryllithium anions, and the grafting level was found to be quite high, close to $40 \%$. Following a nucleophilic addition reaction, Blake and coworkers [35] grafted chlorinated polypropylene (PP) to butyllithium-functionalized MWCNTs with an extent of $31 \mathrm{wt} \%$.
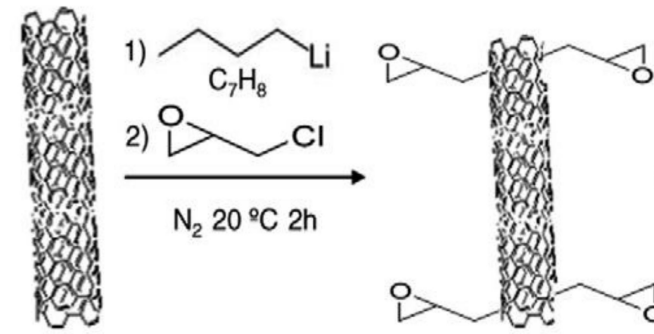

SWCNT-EP

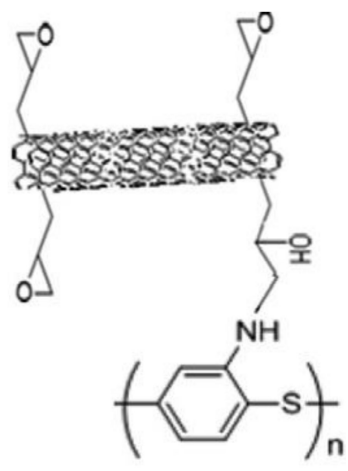

SWCNT-EP/PPS-NH $\mathrm{N}_{2}$

Scheme 3. Synthesis of PPS-NH 2 grafted to epoxy-functionalized SWCNTs. Taken from [33], with permission from Elsevier. 


\subsubsection{Cycloaddition Reactions}

The cycloaddition reaction of polystyrene (PS) derivatives onto functionalized CNTs has been investigated in several studies. In this regard, Qin et al. [36] reported the cycloaddition reaction of azide-terminated PS and SWCNTs, leading to a grafting level of about $2 \%$ polymer chains per CNT carbons. Li and coworkers [37] coupled alkyne-modified SWCNTs with a PS derivative with azide end groups by [3 + 2] Huisgen cycloaddition, resulting in $45 \%$ degree of grafting. These authors also carried out a sulfonation reaction onto the resulting PS-g-SWCNTs, which were found to display high solubility in water and methanol and poor solubility in tetrahydrofuran. SWCNTs were also grafted to conjugated polyacetylenes through cyclization reactions with polymer derivatives carrying azido-functional groups [38]. The resultant modified nanotubes were soluble in common solvents and emitted intense luminescence (quantum yield up to 19\%). The grafting degree estimated by TGA was high, about $85 \mathrm{wt} \%$.

\subsubsection{Amide or Ester Linkage}

The formation of ester or amide bonds between $\mathrm{COOH}$ groups on the CNT surface and polymers or their derivatives is among the most common methods to prepare polymergrafted CNTs. The most used hydroxyl-terminated polymers for the esterification reaction are poly(vinyl alcohol) (PVA) and poly(ethylene glycol) (PEG). Lin et al. [39] anchored PVA chains onto acid-treated SWCNTs and MWCNTs by esterifications activated with dicyclohexylcarbodiimide (DCC). In another study, poly(aminobenzene sulfonic acid) (PABS) and PEG were covalently attached to SWCNTs to form water-soluble graft copolymers with grafting extents of $30 \%$ and $71 \%$, respectively [40]. Diez-Pascual et al. [41] synthesized a hydroxyl polyetheretherketone derivative (PEEK-OH) that was covalently grafted to the surface of acid-treated SWNCTs via a one-step process by activation of the carboxylic groups with DCC and via a two-stage process by acylation of the nanotubes with thionyl chloride (Scheme 4), leading to a grafting degree of about $12 \%$. The former method yielded a nanocomposite with better physicochemical properties. Wang and Tseng [42] synthesized polyurethanes (PU) carrying $\mathrm{COOH}$ groups in the chain extender that experienced esterification reactions with acyl-chloride-activated MWCNTs and reported that the amount of grafted polymer chains was larger when the acid treatment of the nanotubes was longer.
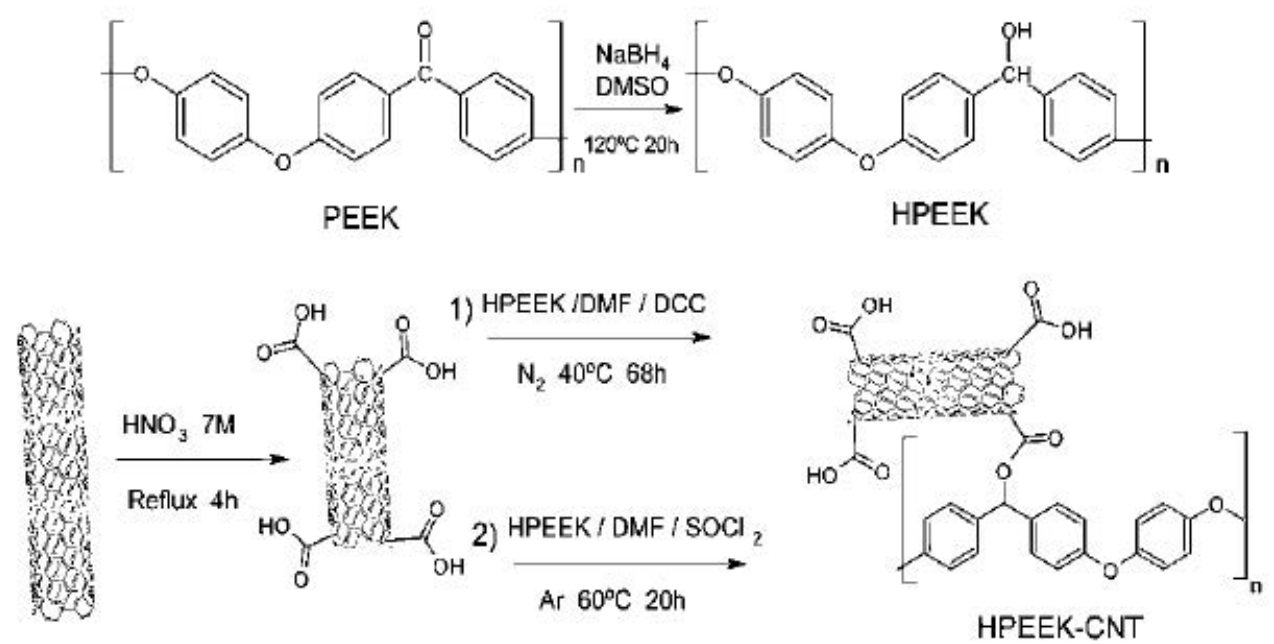

Scheme 4. Synthesis procedure of HPEEK-grafted SWCNTs. Taken from [41], with permission from the Royal Society of Chemistry.

Amidation reactions with nanotubes have been performed using polymers comprising $\mathrm{NH}_{2}$ groups such as poly(N-isopropylacrylamide) (PNIPAAm), polyethyleneimine (PEI), amine-capped poly(D,L-Lactide), polyetherimide, and so forth. For instance, Zhang et al. [43] grafted carboxyl-functionalized MWCNTs to PEI, which was morphologically characterized 
by TEM, showing that the functionalization process does not change the structure of the MWCNTs, since only nanotubes with coating were shown. The grafting ratio varied between $25 \%$ and $36 \%$ depending on the amount of polymer used for the reaction. Oxidized SWCNTs have been grafted with amino-terminated PNIPAAm by carbodiimide-activated reaction, which yielded an $8 \mathrm{wt} \%$ polymer content [44]. Aminated MWCNTs have also been grafted onto poly(methylmethacrylate) (PMMA) via a similar reaction path. The diameters of PMMA-g-MWCNT were on average $50 \mathrm{~nm}$, about 2-3 times larger than those of pristine MWCNTs, as was clearly observed in the SEM images (Figure 3 [45]). PMMA molecules usually have somewhat different molecular weights, which make the surface uneven; hence, the surface roughness of the MWCNTs increased upon PMMA grafting.

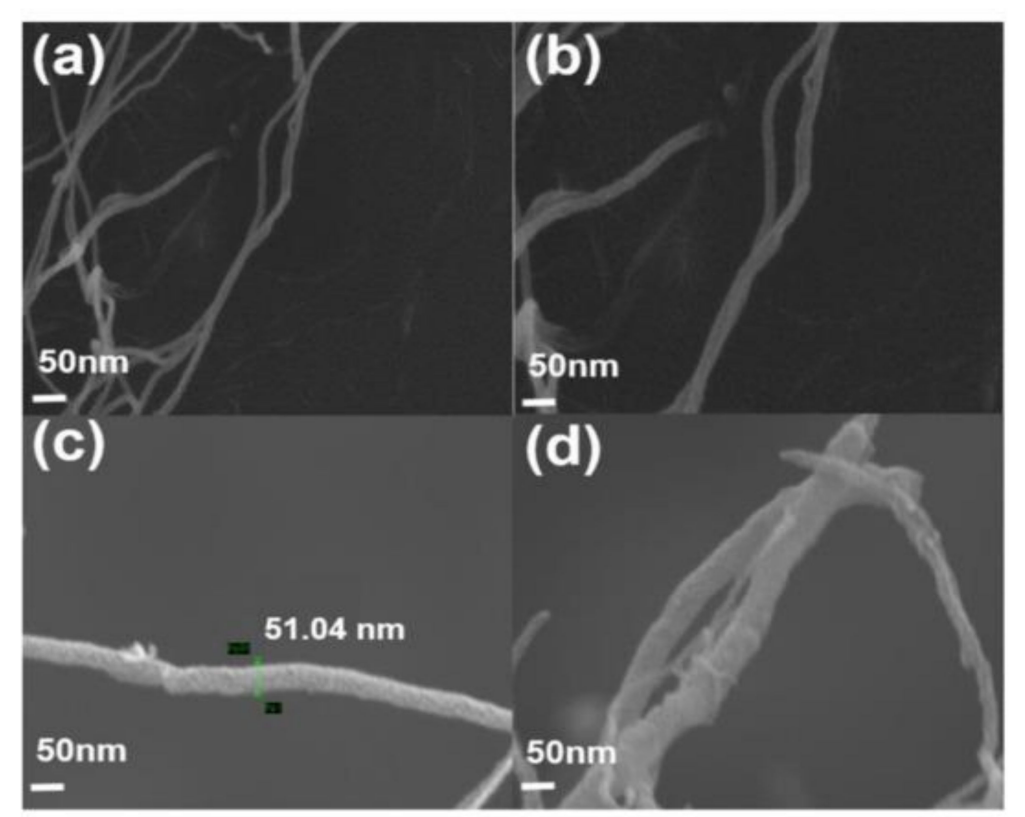

Figure 3. SEM images of MWCNTs: (a,b) pristine MWCNT and (c,d) PMMA-g-MWCNT. Taken from [45], with permission from MDPI.

Lin and coworkers grafted poly(propionylethylenimine-co-ethylimine) (PPEI-EI) to acyl-activated tubes [46] by both direct heating and DCC-initiated amidation. Thermogravimetric analysis experiments indicated $40 \mathrm{wt} \%$ and $30 \mathrm{wt} \%$ polymer loading for these routes, respectively. They also investigated several functionalization methods of $\mathrm{NH}_{2}-\mathrm{PEG}$ derivative onto SWCNTs. The smallest grafting degree was found for straight thermal heating, whereas DCC activation led to the highest grafting grade.

\subsubsection{Other "Grafting To" Approaches}

Other "grafting to" routes have been described, including grafting by a radical pathway, condensation, or sonochemical reactions. For instance, condensation reactions have been employed by numerous researchers to anchor polyurethane (PU) to acid-treated [47] or alkoxysilane-functionalized MWCNTs [48] (Scheme 5). Koshio et al. [49] developed a sonochemical reaction to anchor PMMA to SWCNTs via defects located on the CNT sidewalls, and the chemical linkage was corroborated via infrared spectroscopy. The extent of the reaction was found to be strongly dependent on the solvent. This is a simple approach to obtain modified CNTs. 

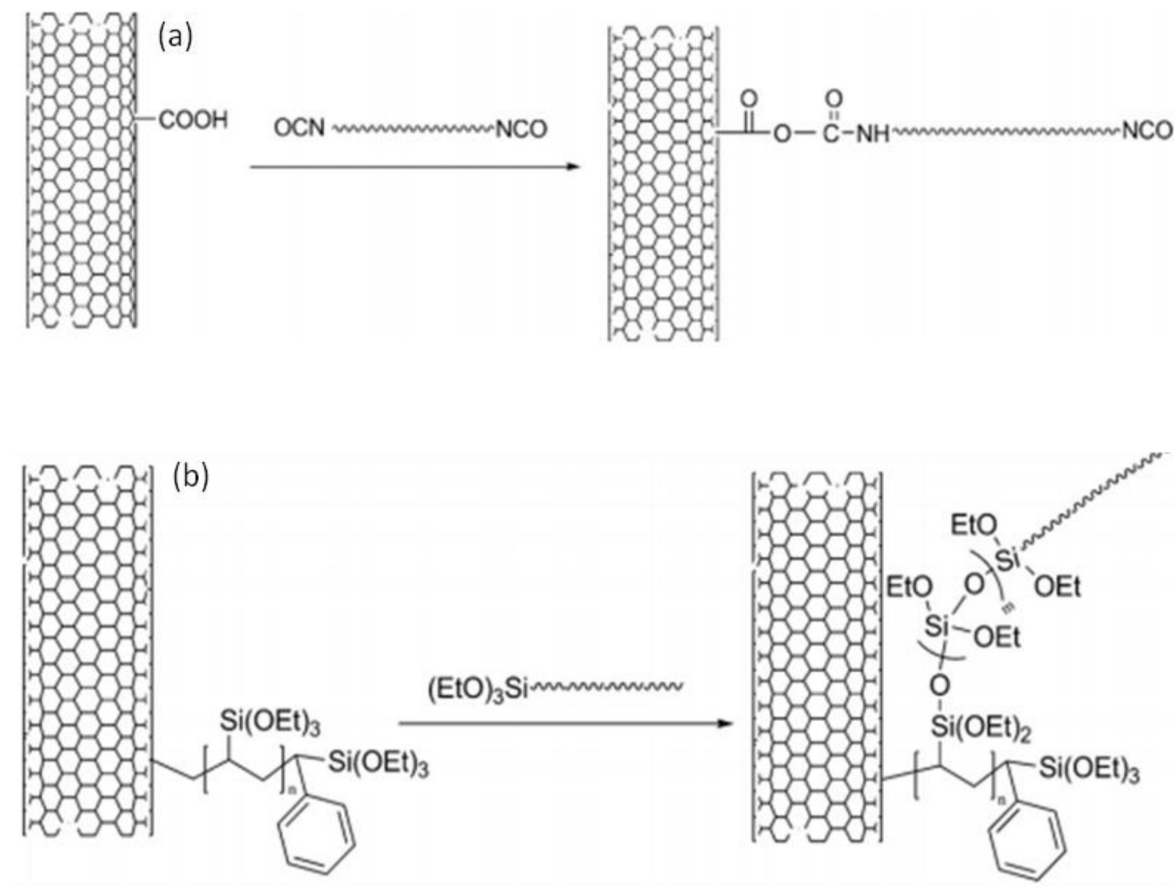

Scheme 5. Schematic representation of (a) the crosslinking of polyurethanes chains with carbon nanotubes. Taken from [47], with permission from Wiley. (b) Siloxane bonding between nanotube and silane-terminated polymer. Taken from [48], with permission from Wiley.

Some representative examples on "grafting to" reactions together with the polymer and the CNT type are summarized in Table 1.

Table 1. Examples of grafting to reactions along with the polymers and CNT type.

\begin{tabular}{|c|c|c|c|c|}
\hline Method & CNT Type & Polymer & Grafting Degree (\%) & Ref. \\
\hline \multirow[t]{2}{*}{ Click coupling } & $\begin{array}{l}\text { alkyne-modified } \\
\text { MWCNT }\end{array}$ & $\begin{array}{c}\text { benzyl chlorinated } \\
\text { polystyrene-co-poly(pchloromethylstyrene) }\end{array}$ & 53 & [28] \\
\hline & $\begin{array}{l}\text { thiol-modified } \\
\text { MWCNT }\end{array}$ & poly[N-(2-hydroxypropyl)methacrylamide] & & [29] \\
\hline \multirow{3}{*}{$\begin{array}{l}\text { Nucleophilic } \\
\text { addition }\end{array}$} & oxidized MWCNT & polystyryllithium & 80 & [30] \\
\hline & $\begin{array}{l}\text { epoxy-modified } \\
\text { SWCNT }\end{array}$ & aminated polyphenylene sulphide & 25 & [33] \\
\hline & $\begin{array}{l}\text { acyl-choride-modified } \\
\text { MWCNT }\end{array}$ & polystyryllithium & 40 & [34] \\
\hline \multirow{4}{*}{$\begin{array}{l}\text { Cycloaddition } \\
\text { reaction }\end{array}$} & $\begin{array}{l}\text { butyllithium-modified } \\
\text { MWCNT }\end{array}$ & chlorinated polypropylene & 31 & [35] \\
\hline & SWCNT & azide-terminated PS & 2 & [36] \\
\hline & $\begin{array}{l}\text { alkyne-modified } \\
\text { SWCNT }\end{array}$ & azide-terminated PS & 45 & [37] \\
\hline & SWCNT & azide-terminated poly(diphenylacetylene) & 85 & [38] \\
\hline \multirow{5}{*}{$\begin{array}{l}\text { Amide and } \\
\text { ester linkages }\end{array}$} & SWCNT/MWCNT & polyvinyl alcohol & & [39] \\
\hline & SWCNT & $\begin{array}{c}\text { polyethylene glycol } \\
\text { poly(aminobenzene sulfonic acid) }\end{array}$ & $\begin{array}{l}71 \\
30\end{array}$ & [40] \\
\hline & oxidized SWCNT & hydroxyl-modified polyetheretherketone & 12 & [41] \\
\hline & $\begin{array}{l}\text { carboxyl-modified } \\
\text { MWCNT }\end{array}$ & polyethyleneimine & $25-36$ & [43] \\
\hline & MWCNT & poly(propionylethylenimine-co-ethylenimine) & $30-40$ & [46] \\
\hline
\end{tabular}




\section{2. "Grafting From" Strategy}

The "grafting from" approach usually comprises polymerization of monomers with active sites (initiators) able of initiating functionality onto MWCNTs or SWCNTs. The benefit of this procedure is that the polymerization is not restricted by steric limitation, allowing the grafting of polymers with a high molecular weight, hence nanocompounds with an elevated grafting extent can be synthesized. Though, it requires a fine control of the reaction conditions as well as the amounts of initiator and substrate. Some representative examples on "grafting from" reactions are described in the following sections.

\subsubsection{Atom Transfer Radical Polymerization (ATRP)}

The ATRP is a way of creating a carbon-carbon bond with a transition metal catalyst. It allows the polymerization of an extensive variety of monomers with different chemical functionalities and offers good control of molecular weight, molecular architecture, and polymer composition with a low polydispersity. However, it presents some drawbacks, including the high catalyst concentration required for the reaction. This catalyst usually comprises a copper halide and an amine-based ligand. The removal of the copper upon polymerization can be tedious and costly, thus limiting ATRP use at a large scale. It is an air-sensitive reaction, difficult to be carried out in aqueous media.

This technique has been employed by different authors for grafting PEG, PMMA, and poly(polyethylene glycol methyl ether methacrylate), P(PEGMA), to CNTs [50-53]. The strategy for grafting polymers from the CNTs by ATRP includes four stages, as depicted in Figure 4 [51]. First, acyl-chloride-functionalized MWCNTs (MWCNTs-COCl) are synthesized via reaction of thionyl chloride with carboxyl-acid-functionalized MWCNTs (MWNTs-COOH); then, these react with glycol, resulting in MWCNTs-OH. Subsequently, the hydroxyl-functionalized MWCNTs react with 2-bromo-2-methylpropionyl bromide, leading to MWCNTs-Br, which are then grafted onto the monomer (i.e., MMA), to yield MWCNTs-g-PMMA. Grafting degrees in the range of $32 \%-82 \%$ were obtained depending on the $\mathrm{CNT} /$ polymer weight ratio.

Yao et al. [52] described an in situ polymerization method to attach MMA chains to CNTs via former functionalization with alkyl bromide groups via a two-step approach. The functionalized CNTs acted as initiators for ATRP of MMA, resulting in a PMMA-SWCNT nanocomposite with a high glass transition temperature albeit insoluble in common organic solvents. Baskaran et al. [53] described ATRP of polystyrene (PS) and PMMA from MWCNTs. The quantity of PMMA covalently anchored was $70 \mathrm{wt} \%$, whereas for PS, it increased from 18 to $34 \mathrm{wt} \%$ with raising the initiator content. Thus, it appears that the polymer molecular weight can be controlled via adjusting the initiator content. Liu and coworkers [54] carried out the ATRP polymerization of PMMA with SWCNTs with a grafting degree of $17 \mathrm{wt} \%$.

\subsubsection{Reversible Addition-Fragmentation Chain Transfer (RAFT)}

An alternative tactic was to chemically prepare polymer-grafted CNTs is the reversible addition-fragmentation chain transfer (RAFT polymerization). In this path, the molecular mass of the polymer is directly related to the monomer proportion, and there is a constricted molecular mass distribution. It operates under mild conditions; polymerization can be attained by several approaches including emulsion, bulk, or suspension polymerization, and the structures are well-defined. The main advantages are that it is appropriate to a varied type of monomers and it allows controlling the polymerization of monomers soluble in water. The disadvantages are the need to select a RAFT agent for the specific polymerization and processing conditions. By means of this tactic, Cui and coworkers [55] employed 2,2-azobisisobutyronitrile (AIBN) as initiator for grafting PS chains onto MWCNTs. TEM micrographs of the samples corroborated the development of a core-shell nanostructure, with a core of MWCNTs and a shell of polymeric layer. This method may be useful for the development of core-shell polymer nanocomposites. Similarly, Hong et al. [56] grafted PNiPAAM to MWCNTs; the quantity of polymer grafted grew with increasing 
polymerization time. The MWCNT-g-PNiPAAM had good solubility in water, chloroform, and tetrahydrofuran. TEM pictures also displayed that the MWCNT-g-PNiPAAM was distributed separately, demonstrating that the tube bundles via RAFT polymerization were disentangled into individual tubes. The developed nanocomposite had a PNIPAAM shell, which was responsive to changes in temperature.
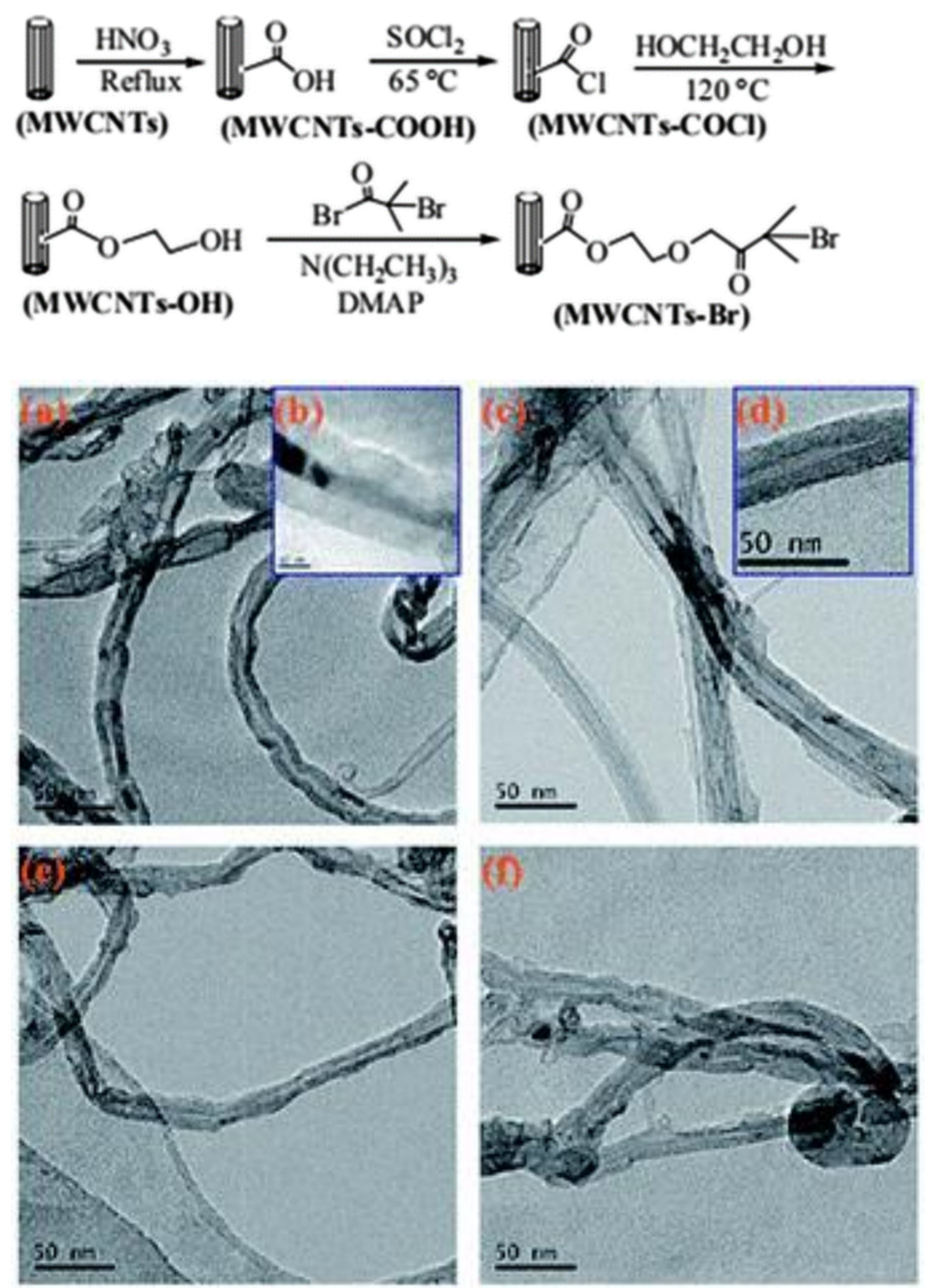

Figure 4. Top: Schematic representation for grafting polymers from MWCNTs via atom transfer radical polymerization (ATRP). Bottom: TEM images of original MWCNTs (a,b), MWCNTs-g-PS (c,d), MWCNTs-g-PMMA, (e) and MWCNTs-g-P(P(PEGMA) (f). Taken from [51], with permission from the Royal Society of Chemistry.

$\mathrm{Xu}$ et al. [57] also developed a core-shell hybrid nanostructure with a backbone of MWCNTs and a squishy shell of hairy-like PMMA, via synthesis of alkyl-bromide MWCNTs that reacted with PhC(S)SMgBr to yield MWNT-SC(S)Ph. Then, MMA chains were polymerized with AIBN as initiator (Scheme 6). 


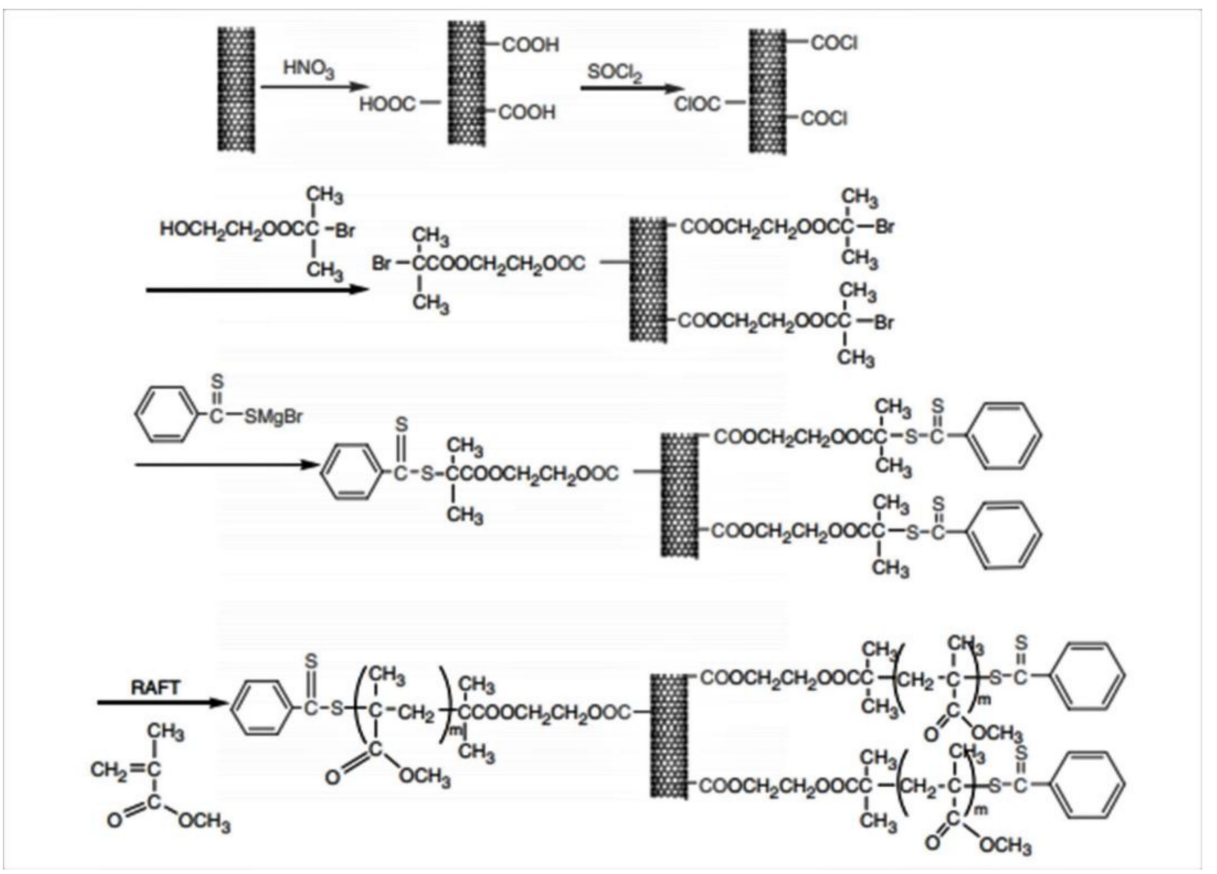

Scheme 6. Surface-initiated reversible addition-fragmentation chain transfer (RAFT) polymerization of MMA from MWNTs. Taken from [57], with permission from Wiley.

The quantity of PMMA anchored to MWCNTs estimated via thermogravimetric analysis was between $22 \%$ and $67 \%$ depending on the PMMA/CNT ratio, indicating that the process is tailorable. Furthermore, the nanocomposites were properly dispersed in organic low / medium polar solvents such as $\mathrm{C}_{6} \mathrm{H}_{5} \mathrm{CH}_{3}, \mathrm{CHCl}_{3}$, or THF. The grafting process was monitored by SEM/TEM (Figure 5). In the images of raw MWCNTs (Figure 5a,b), individual tubes separated from each other were found. Afterward oxidation by $\mathrm{HNO}_{3}$ for $24 \mathrm{~h}$ (Figure 5c,d), most of the tubes retain their tubular structure with mean lengths of the order of micrometers, although many defects and holes were formed (oxidation took place both at the outer and inner walls, providing many reactive sites). For the MWCNT-gPMMA (Figure 5e,f), a core-shell structure with MWCNTs covered by amorphous material was found, attributed to the attached PMMA chains.
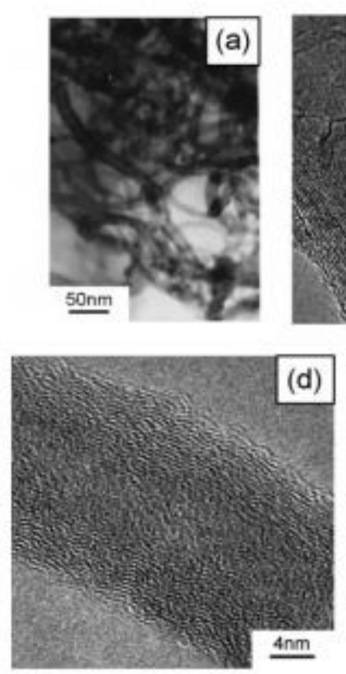
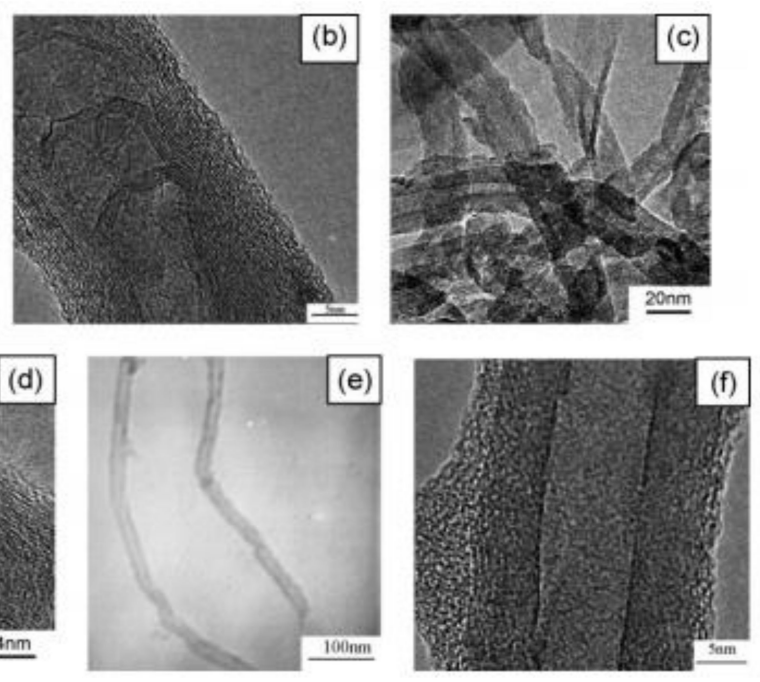

Figure 5. TEM images of raw MWCNTs $(\mathbf{a}, \mathbf{b})$, oxidized MWCNT $(\mathbf{c}, \mathbf{d})$, and PMMA-g-MWCNTs (e,f) at different magnifications. Taken from [57], with permission from Wiley. 


\subsubsection{Ring Opening Polymerization (ROP)}

Polymerization via ring opening (ROP) is a method in which one termination of the polymer chain bears a group suitable to react with cyclic monomers. The end groups in the obtained polymer are conditioned by the initiator and termination reactions. Different researchers have also used this method for anchoring polycaprolactone (PCL) to functionalized nanotubes.

Qu et al. [58] grafted nylon 6 onto SWCNTs via a two-step process: first, caprolactammodified SWCNTs were synthesized, which showed increased suspendibility in chloroform. Then, they were mixed with more caprolactam as a monomer and $\mathrm{Na}$ as an initiator. Similarly, Yang and coworkers [59] attached caprolactam to isocyanate-functionalized MWCNTs via anionic ROP, and found that the percentage of polymer grafting raised with increasing polymerization time, reaching a maximum close to $65 \%$ after $6 \mathrm{~h}$. This tactic can be useful for linking other monomers that follow a similar polymerization mechanism as PCL.

\subsubsection{Free Radical Polymerization}

One of the most flexible kinds of chain-growth polymerization is the free radical, which has the advantage of being adequate for most of vinyl monomers though permits little control of chain architecture, molecular mass, and polydispersity. The main drawback of the free radical grafting is the low selectivity of the radical center, especially at high temperatures (in the range of $150-200^{\circ} \mathrm{C}$, required for extrusion of polyethylene), leading to side reactions such as coupling and chain scission [60]. Moreover, performing this chemical modification by reactive processing brings in many constraints inherent to the processing (e.g., short reaction time, viscous dissipation, and high temperature). For instance, CNT functionalization can be performed via in situ free radical polymerization of styrene or MMA. According to this procedure, Shaffer and Koziol [61] grafted oxidized MWCNTs with PS. The MWCNTs were first dispersed in water; then, a radical initiator and styrene monomers were added. Grafting proportions between $50 \%$ and $90 \%$ were yielded based on the original MWCNT loading. Yang et al. [62] mixed acyl-chloride-functionalized MWCNTs and allylamine in order to synthesize vinyl-functionalized-MWCNTs via an amidation reaction, and subsequently carried out the in situ free radical polymerization of styrene to make MWCNT-g-PS. However, only $1 \%$ of the carbon atoms of the MWCNTs were modified. The compound was highly soluble in low/medium polar organic solvents such as THF, DMF, chloroform, toluene, and so forth even after seven days (Figure 6). Qin et al. [63] reported the grafting of SWCNTs by poly(sodium 4-styrenesulfonate) (PSS) using the same approach, and a $45 \mathrm{wt} \%$ of grafted PPS was attained. Likewise, PMMA chains were anchored onto SWCNTs in a poor solvent for the polymer. The in situ polymerization of MMA in supercritical $\mathrm{CO}_{2}$ was reported by Yue and coworkers [64]. The SWCNTs were initially functionalized with amino ethylmethacrylate by amidation of oxidized CNTs. The diffusion of monomers was improved by the supercritical $\mathrm{CO}_{2}$, which also promoted the growth of PMMA chains. This resulted in significant nanotube disentanglement and better distribution within the matrix, as revealed by microscopic observations. 


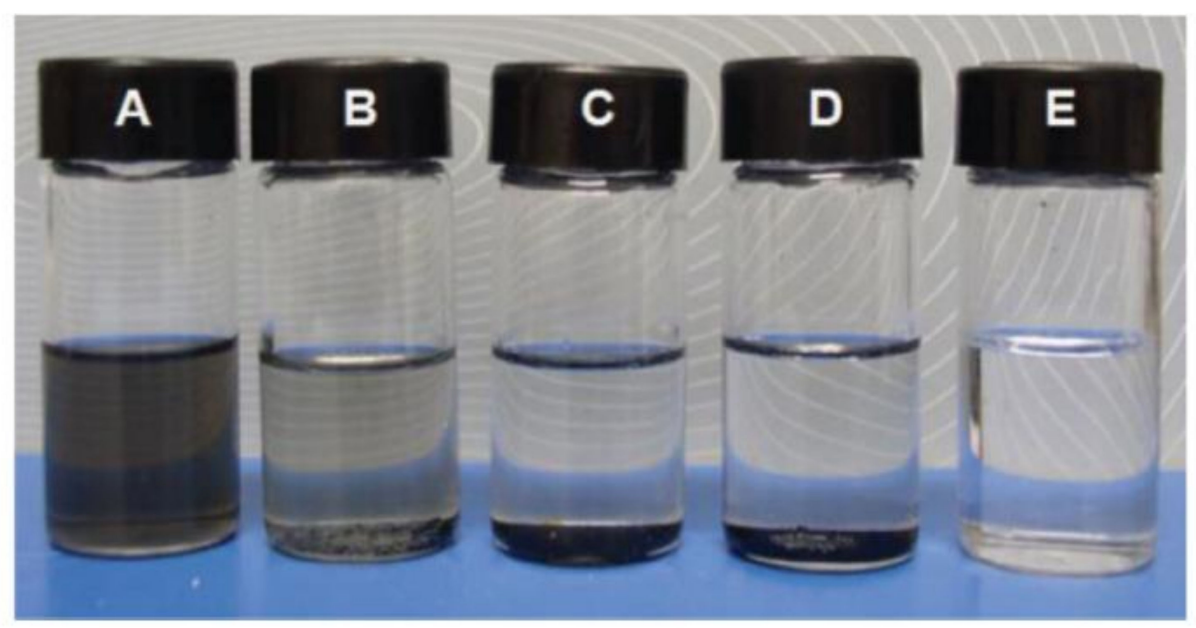

Figure 6. Image showing the solution stability of: (A) PS-g-MWCNT ( $t=7$ days), (B) PS/MWCNT $(t=5 \mathrm{~h}),(\mathrm{C}) \mathrm{MWCNT}-\mathrm{COOH}(t=5 \mathrm{~h}),(\mathbf{D}) \mathrm{MWCNT}-\mathrm{CH}=\mathrm{CH} 2(t=5 \mathrm{~h})$, and (E) dPS (defunctionalized PS from PS-g-MWCNT) with the same concentration of $1.0 \mathrm{mg} / \mathrm{mL}$. Reprinted from [62], with permission from Wiley.

Table 2 collects different grafting from reactions together with the polymer and corresponding CNT type.

Table 2. Examples of "grafting from" reactions along with the polymers and CNT type.

\begin{tabular}{|c|c|c|c|c|}
\hline Method & CNT Type & Polymer & Grafting Degree (\%) & Ref. \\
\hline \multirow[t]{5}{*}{ ATRP } & alkyl-modified MWCNT & poly(methyl methacrylate) & $32-82$ & {$[50]$} \\
\hline & alkyl-modified SWCNT & poly(methyl methacrylate) & & [52] \\
\hline & bromide-modified MWCNT & poly(methyl methacrylate) & 70 & [53] \\
\hline & bromide-modified MWCNT & polystyrene & $18-33$ & [54] \\
\hline & SWCNT & poly(methyl methacrylate) & 17 & [54] \\
\hline RAFT & bromide-modified MWCNT & poly(methyl methacrylate) & $22-67$ & [57] \\
\hline ROP & isocyanate-modified MWCNTs & polyamide & 68 & [59] \\
\hline \multirow{2}{*}{$\begin{array}{c}\text { Free radical } \\
\text { polymerization }\end{array}$} & oxidized MWCNTs & polystyerene & $50-90$ & {$[61]$} \\
\hline & SWCNTs & $\begin{array}{c}\text { poly(sodium } \\
\text { 4-styrenesulfonate) }\end{array}$ & 45 & [63] \\
\hline
\end{tabular}

\section{Applications of Polymer-Functionalized CNTs}

Specific applications of polymer-grafted CNTs include biomedical, biosensors, membranes, energy storage, EMI shielding, and so forth, which are briefly discussed below.

\subsection{Biosensors and Biomedical Applications}

CNTs have great potential in electrochemical biosensors and nanoscale electronic devices due to their small size, enhanced electron transfer property, and high surface area. However, due to the poor solubility of CNTs in many solvents, especially in water, their applications in fields such as biomedicine, biomedical imaging, and cancer therapy are limited. Hence, surface modification is necessary for CNT materials to improve their compatibility, solubility in common solvents, and selective binding capability to biotargets. This can be overcome via the attachment of hydrophilic polymeric segments that improve their solubility in aqueous media [65]. For instance, MWCNTs grafted to poly(amidoamine) PAMAM dendrimers have been developed for cancer cell targeting and imaging [66]. Furthermore, conducting polymers such as polyaniline (PANI) grafted to modified CNTs have been used to develop biosensors owed to their conductivity and functional group selectivity [67]. Yang et al. [68] built a glucose biosensor by grafting specially selected 
vinyl polymers on the surface of CNTs through radiation-induced graft polymerization, RIGP, Figure 7. The monomers employed were acrylic acid (AAc), methacrylic acid (MAc), glycidyl methacrylate (GMA), maleic anhydride (MAn), and 4-vinylphenylboronic acid (VPBAc). The poly (4-vinylphenylboronic acid) (PVPBAc) grafted CNT biosensor exhibited much better sensitivity, selectivity, reproducibility, and response time compared to the rest.

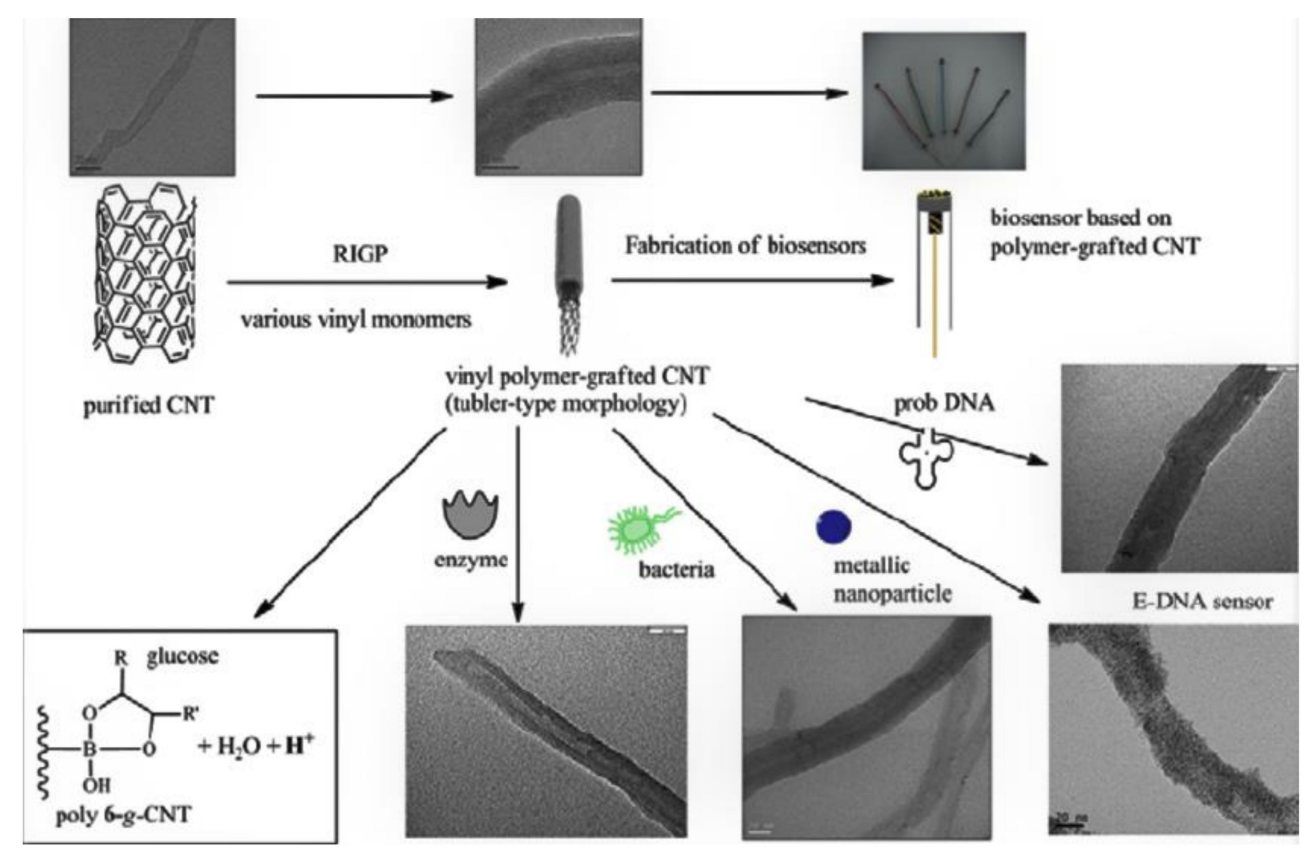

Figure 7. Schematic representation of the synthesis of biosensors based on vinyl-polymer-grafted MWCNT. Adapted from [68].

\subsection{Membranes}

The role of carbon nanotubes (CNTs) as fillers in membrane matrices has recently attracted a great amount of interest to solve issues between permeability and selectivity, and also fouling problems in membrane filtration applications [69]. Their fullerene form is crucial to provide a higher pore size and porosity in membrane structures. However, the hydrophobicity characteristic of CNTs and agglomerating tendency limit their use in membranes. Functionalization of CNTs with polymers is expected to solve those problems. Thus, polymer grafted CNTs have been designed for water/oil separation. For instance, hydrophobic PS and hydrophilic poly(N,N-dimethylaminoethyl methacrylate) (PDMAEMA) have been grafted from the sides of a CNT membrane via photopolymerization to obtain Janus polymer/CNT membranes [70]. This type of membrane has an outstanding ability to separate oil from water due to the difference in the wettability of the polymers. Soyekwo et al. [71] developed highly permeable nanofiltration membranes for purification and separation applications by grafting crosslinked PEI onto a carboxylated CNT layer incorporated into a macroporous cellulose acetate substrate. Crosslinking enhances the polymer interaction with the CNT interlayer, hence providing mechanical strength and sustains the membrane pore structure during pressure-driven filtration. The membranes exhibited excellent separation of organic molecules and long-term filtration stability.

\subsection{Energy Storage}

Currently, polymer electrolyte membrane fuel cells (PEMFC) have become a key issue in the energy storage field since they can substitute conventional energy sources. The major component of a PEMFC is a bipolar plate, typically made of polypropylene (PP) nanocomposites. The addition of PP-g-MWCNT can result in improved mechanical strength, electrical conductivity, and contact resistance of the bipolar plates [72]. An 
alternative solution for energy demands is dye-sensitized solar cells (DSSCs), in which Ptbased transparent electrode was used as a counterelectrode. However, due to its tendency to corrosion and high cost, it has been replaced by CNTs. Grafting CNTs with polymers is an effective way to solve these issues. For instance, poly(styrene sulfonate) (PSS) was grafted to MWCNTs via radical polymerization; then, thin layers were deposited via spraying technique to be used as electrodes in DSSCs [73] (Figure 8). The energy conversion efficiency was about $6 \%$ and the charge transfer resistance was better than that of a cell with Pt. The cell was cheaper and more environmentally friendly.

(A)

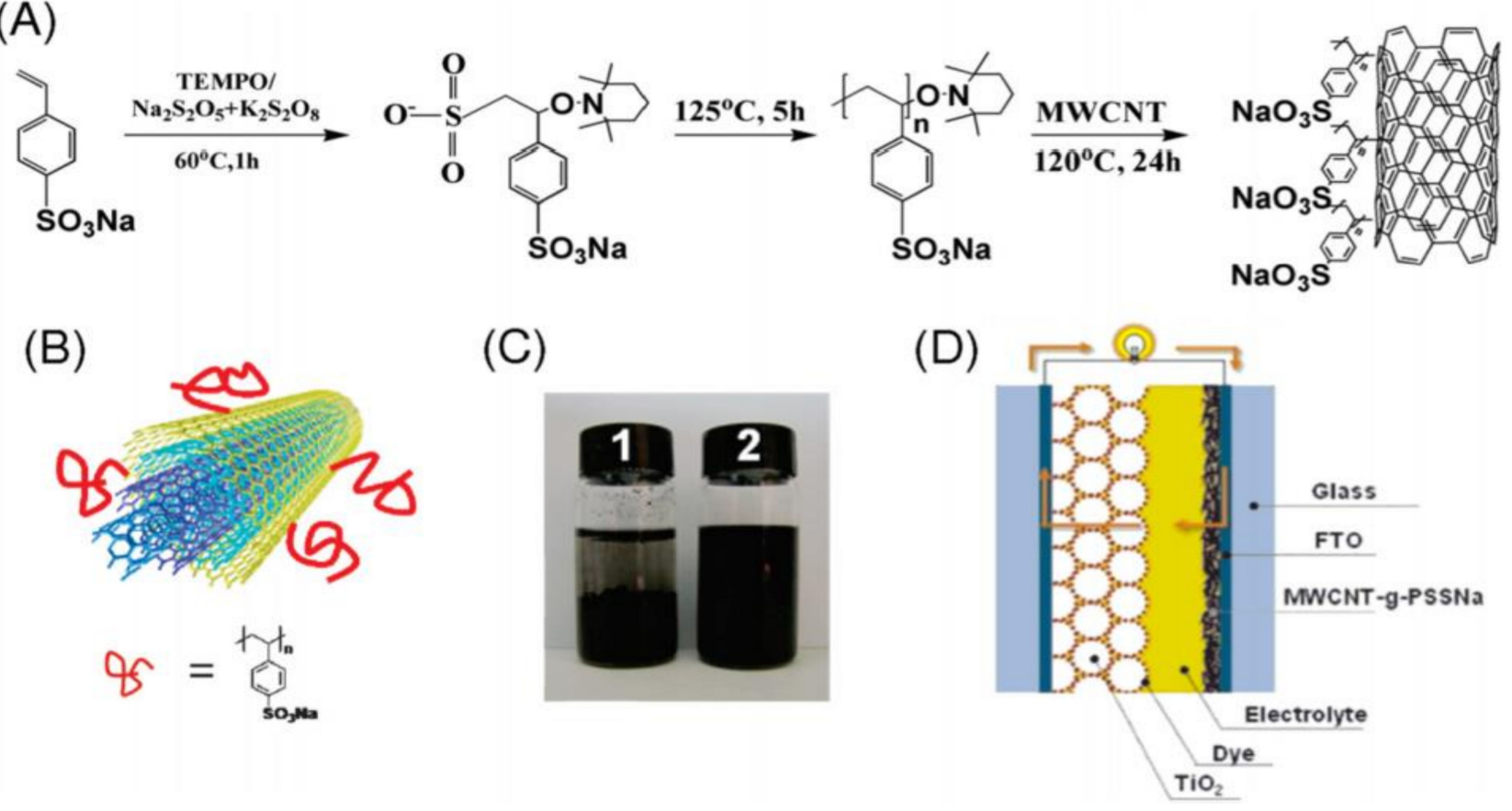

Figure 8. (A) Synthesis of MWCNT-g-PSS, (B) structure of MWCNT-g-PSS, (C) photographs of pristine MWCNTs (1), and MWCNT-g-PSS, (2), in water. (D) Schematic diagram of dye-sensitized solar cells. Adapted from [73], with permission from the American Chemical Society.

\subsection{EMI Shielding}

Polymer/CNT nanocomposites are suitable for electromagnetic shielding devices at even low CNT loading [74]. However, due to the strong tendency of CNT agglomeration, it is difficult to get a conducting network in the composite; in this regard, polymer-grafted CNT composites have emerged as an excellent alternative [75]. Hayashida and Matsuoka synthesized PMMA-g-MWCNT by ATRP and incorporated it into a PMMA matrix. The resulting nanocomposites showed good shielding effectiveness of $29 \mathrm{~dB}$ at $110 \mathrm{GHz}$ [76]. Poothanari et al. [77] used polypropylene-grafted maleic anhydride (PP-g-MA), as compatibilizer for polycarbonate (PC)/polypropylene (PP) polymer blend. The compatibilized $\mathrm{PC} / \mathrm{PP}$ blend of $2 \mathrm{~mm}$ thickness displayed an EMI SE of $54.78 \mathrm{~dB}$ at $3 \mathrm{GHz}$ for $10 \mathrm{wt} \%$ MWCNT loading.

\section{Conclusions and Future Perspectives}

CNTs are attractive for many disciplines ranging from chemistry, physics, and biology to material science as a result of their exceptional characteristics and far-ranging applications in diverse fields including optoelectronics, biomedical, and biotechnology. However, their strong agglomerating tendency and insolubility in common solvents limit their applications. Several tactics have been implemented to face these issues, being one of the most crucial the nanotube functionalization with polymers, either by means of "covalent" or "noncovalent" paths based on the formation of covalent bonds or weaker interactions (i.e., 
electrostatic forces or van der Waals forces), respectively. The covalent functionalization can be carried out by anchoring reactive groups on the surface of both polymer and CNT and allowing them to react (grafting to) or by placing chemical groups (initiators) on the nanotube surface followed by in situ polymerization of the monomer on the surface (grafting from). A number of strategies including coupling and nucleophilic addition reactions, amide and ester, ATRP, RAFT, ROP, free radical polymerization, and so forth have been reported. The main advantages and disadvantages of each approach are summarized in Table 3. All of them result in a nanocomposite with increased solubility, high interaction between polymer and CNT, and effective CNT debundling. Polymer-grafted CNTs display superior thermal stability, electromagnetic shielding ability, high tensile strength, and Young's modulus, whereas less electrical conductivity when compared to the pristine tubes. Even though many investigations have been devoted to the applications of polymer-grafted CNTs, real product development is in the primary stage. Ongoing research is crucial to project novel environmentally friendly, selective, cost-effective, and scalable functionalization routes that could be implemented in industry. The sort of solvent, polymer molecular mass, viscosity, and loading are crucial factors that need to be taken into account when searching for innovative polymers suitable for specific nanotube functionalization. The optimization of all the factors is essential to achieve nanotube-based systems with flexible architectures, novel functionalities, and better properties. Furthermore, little knowledge is still available regarding nanotube toxicity. Consequently, deeper studies on their harmfulness to the human body are urgently required prior to any biomedical application. Likewise, the high price of CNTs prevents their spread use in composite technology. In short, the basic encounter to attain high performance composites with individual CNT dispersion and strong adhesion to the polymer matrix relies on a custom design of CNT functionalization schemes targeted on the application.

Table 3. Main advantages and limitations of "grafting from" and "grafting to" approaches.

\begin{tabular}{|c|c|c|}
\hline Method & Advantages & Limitations \\
\hline Click coupling & $\begin{array}{c}\text { versatile, simple, } \\
\text { high reaction rates } \\
\text { low temperatures, } \\
\text { easily removable byproducts }\end{array}$ & $\begin{array}{l}\text { random coupling sites } \\
\text { need metal catalyst } \\
\text { some reagents are expensive }\end{array}$ \\
\hline Nucleophilic addition & $\begin{array}{l}\text { versatile, preformed commercial } \\
\text { polymers can be used }\end{array}$ & $\begin{array}{l}\text { prone to many side } \\
\text { reactions } \\
\text { nonuseful for composites } \\
\text { insoluble in water } \\
\text { restricted to polymers with }\end{array}$ \\
\hline Cycloaddition reaction & versatile, one-pot synthesis & $\begin{array}{l}\text { highly reactive groups } \\
\text { need metal catalyst }\end{array}$ \\
\hline Amide and ester linkages & $\begin{array}{l}\text { Versatile, simple, } \\
\text { mild conditions, } \\
\text { short reaction time }\end{array}$ & $\begin{array}{l}\text { expensive reagents } \\
\text { require activation } \\
\text { low grafting yield } \\
\text { generate byproducts }\end{array}$ \\
\hline ATRP & $\begin{array}{l}\text { control of molecular weight, } \\
\text { architecture, and composition } \\
\text { low polydispersity }\end{array}$ & $\begin{array}{l}\text { high catalyst concentration } \\
\text { difficult to be performed } \\
\text { in aqueous media }\end{array}$ \\
\hline RAFT & $\begin{array}{c}\text { versatile, mild conditions, } \\
\text { useful for monomers } \\
\text { soluble in water }\end{array}$ & $\begin{array}{c}\text { need a specific RAFT agent } \\
\text { need to optimize } \\
\text { processing conditions }\end{array}$ \\
\hline ROP & $\begin{array}{l}\text { useful for high-molecular } \\
\text {-weight polymers } \\
\text { controlled chain length }\end{array}$ & $\begin{array}{c}\text { slow, generate byproducts due } \\
\text { to intermolecular reactions } \\
\text { expensive }\end{array}$ \\
\hline Free radical polymerization & versatile, simple, low cost & low selectivity, side reactions \\
\hline
\end{tabular}


Funding: Financial support from the Comunidad de Madrid en el marco del Convenio Plurianual con la Universidad de Alcalá en la línea de actuación "Estímulo a la Excelencia para Profesores Universitarios Permanentes", Ref. EPU-INV/2020/012, is acknowledged.

Institutional Review Board Statement: Not applicable.

Informed Consent Statement: Not applicable.

Data Availability Statement: The data presented in this study are available on request from the corresponding author.

Conflicts of Interest: The authors declare no conflict of interest.

\section{References}

1. Eatemadi, A.; Daraee, H.; Karimkhanloo, H.; Kouhi, M.; Zarghami, N.; Akbarzadeh, A.; Abasi, M.; Hanifehpour, Y.; Joo, S.Y. Carbon nanotubes: Properties, synthesis, purification, and medical applications. Nanoscale Res. Lett. 2014, 9, 393. [CrossRef]

2. Diez-Pascual, A.M.; Naffakh, M.; Marco, C.; Ellis, G.; Gómez-Fatou, M.A. High performance nanocomposites based on polyetherketones. Prog. Mater. Sci. 2012, 57, 1106-1190. [CrossRef]

3. Diez-Pascual, A.M.; Diez-Vicente, A.L. Development of nanocomposites reinforced with carboxylated poly(ether ether ketone) grafted to zinc oxide with superior antibacterial properties. ACS Appl. Mater. Interfaces 2014, 6, 3729-3741. [CrossRef]

4. Guadagno, L.; Raimondo, M.; Naddeo, C.; Di Bartolomeo, A.; Lafdi, K. Influence of multiwall carbon nanotubes on morphological and structural changes during UV irradiation of syndiotactic polypropylene films. J. Polym. Sci. B Polym. Phys. 2012, 50, 963-975. [CrossRef]

5. Bugatti, V.; Viscusi, G.; Di Bartolomeo, A.; Iemmo, L.; Zampino, D.C.; Vittoria, V.; Gorrasi, G. Ionic liquid as dispersing agent of LDH-carbon nanotubes into a biodegradable vinyl alcohol polymer. Polymers 2020, 12, 495. [CrossRef] [PubMed]

6. Dervishi, E.; Li, Z.; Xu, Y.; Saini, V.; Biris, A.R.; Lupu, D.; Biris, A.S. Carbon nanotubes: Synthesis, properties, and applications. Part. Sci. Technol. 2009, 27, 107-125. [CrossRef]

7. Baldrighi, M.; Trusel, M.; Tonini, R.; Giordani, S. Carbon nanomaterials interfacing with neurons: An in vivo perspective. Front. Neurosci. 2016, 10, 250. [CrossRef] [PubMed]

8. Díez-Pascual, A.M.; Naffakh, M.; Gómez, M.A.; Marco, C.; Ellis, G.; Martínez, M.T.; Ansón, A.; González-Domínguez, J.M.; Martínez-Rubi, Y.; Simard, B. Development and characterization of PEEK/carbon nanotube composites. Carbon 2009, 47, 3079-3090. [CrossRef]

9. Tsang, S.C.; Chen, Y.K.; Harris, P.J.F.; Green, M.L.H. A simple chemical method of opening and filling carbon nanotubes. Nature 1994, 372, 159-162. [CrossRef]

10. Datsyuk, V.; Kalyva, M.; Papagelis, K.; Parthenios, J.; Tasis, D.; Siokou, A.; Kallitsis, J.; Galiotis, C. Chemical oxidation of multi-walled carbon nanotubes. Carbon 2008, 46, 833-840. [CrossRef]

11. González-Domínguez, J.M.; Anson-Casaos, A.; Díez-Pascual, A.M.; Ashrafi, B.; Naffakh, M.; Backman, D.; Stadler, H.; Johnston, A.; Gómez, M.; Matínez, M.T. Solvent-free preparation of high-toughness epoxy-SWNT composite materials. ACS Appl. Mater. Interfaces 2011, 3, 1441-1450. [CrossRef]

12. Park, T.J.; Banerjee, S.; Hemraj-Benny, T.; Wong, S.S. Purification strategies and purity visualization techniques for single-walled carbon nanotubes. J. Mater. Chem. 2006, 16, 141-154. [CrossRef]

13. Haddon, R.C.; Sippel, J.; Rinzler, A.G.; Papadimitrakopoulos, F. Purification and separation of carbon nanotubes. MRS Bull. 2004, 29, 241-252. [CrossRef]

14. Ma, P.C.; Siddiqui, N.A.; Marom, G.; Kim, J.K. Dispersion and functionalization of carbon nanotubes for polymer-based nanocomposites: A review. Compos. Part A 2010, 41, 1345-1367. [CrossRef]

15. Gorrasi, G.; Sarno, M.; Di Bartolomeo, A.; Sannino, D.; Ciambelli, P.; Vittoria, V. Incorporation of carbon nanotubes into polyethylene by high energy ball milling: Morphology and physical properties. J. Polym. Sci. B Polym. Phys. 2007, 45, 597-606. [CrossRef]

16. Chen, Z.; Dai, X.J.; Magniez, K.; Lamb, P.R.; de Celis Leal, D.R.; Fox, B.L.; Wang, X. Improving the mechanical properties of epoxy using multiwalled carbon nanotubes functionalized by a novel plasma treatment. Compos. Part A 2013, 45, 145-152. [CrossRef]

17. Hirsch, A. Functionalization of carbon nanotubes. Angew. Chem. Int. Ed. 2002, 41, 1853-1859. [CrossRef]

18. Díez-Pascual, A.M.; Naffakh, M.; Gómez, M.A.; Marco, C.; Ellis, G.; Martínez, M.T.; Ansón, A.; González-Domínguez, J.M.; Martínez-Rubi, Y.; Simard, B.; et al. The influence of a compatibilizer on the thermal and dynamic mechanical properties of PEEK/carbon nanotube composites. Nanotechnology 2009, 20, 315707. [CrossRef] [PubMed]

19. Huang, W.; Lin, Y.; Taylor, S.; Gaillard, J.; Rao, A.M.; Sun, Y.P. Sonication-assisted functionalization and solubilization of carbon nanotubes. Nano Lett. 2002, 2, 231-234. [CrossRef]

20. Williams, J.; Broughton, W.; Koukoulas, T.; Rahatekar, S. Plasma treatment as a method for functionalising and improving dispersion of carbon nanotubes in epoxy resins. J. Mater. Sci. 2013, 48, 1005-1013. [CrossRef]

21. Chen, J.; Liu, B.; Gao, X.; Xu, D. A review of the interfacial characteristics of polymer nanocomposites containing carbon nanotubes. RSC Adv. 2018, 8, 28048-28085. [CrossRef]

22. Sinnott, S.B. Chemical Functionalization of Carbon Nanotubes. J. Nanosci. Nanotechnol. 2002, 2, 113-123. [CrossRef] 
23. Basheer, B.V.; George, J.J.; Siengchin, S.; Parameswaranpillai, J. Polymer grafted carbon nanotubes—Synthesis, properties, and applications: A review. Nano-Struct. Nano-Objects 2020, 22, 100429. [CrossRef]

24. Sireesha, M.; Babu, V.J.; Kiran, A.S.K.; Ramakrishna, S.A. review on carbon nanotubes in biosensor devices and their applications in medicine. Nanocomposites 2018, 4, 36-57. [CrossRef]

25. Gonzalez-Dominguez, J.M.; Castell, P.; Bespin-Gascon, S.; Anson-Casaos, A.; Diez-Pascual, A.M.; Gomez-Fatou, M.A.; Benito, A.M.; Maser, W.K.; Martinez, M.T. Covalent functionalization of MWCNTs with poly(p-phenylene sulphide) oligomers: A route to the efficient integration through a chemical approach. J. Mater. Chem. 2012, 22, 21285-21297. [CrossRef]

26. Spitalsky, Z.; Tasis, D.; Papagelis, K.; Galiotis, C. Carbon nanotube-polymer composites: Chemistry, processing, mechanical and electrical properties. Prog. Polym. Sci. 2010, 35, 357-401. [CrossRef]

27. Nish, A.; Hwang, J.Y.; Doig, J.; Nicholas, R.J. Highly selective dispersion of single-walled carbon nanotubes using aromatic polymers. Nat. Nanotechnol. 2007, 2, 640-646. [CrossRef] [PubMed]

28. Xie, L.; Xu, F.; Qiu, F.; Lu, H.; Yang, Y. Single-walled carbon nanotubes functionalized with high bonding density of polymer layers and enhanced mechanical properties of composites. Macromolecules 2007, 40, 3296-3305. [CrossRef]

29. You, Y.Z.; Hong, C.Y.; Pan, C.Y. Functionalization of carbon nanotubes with well-defined functional polymers via thiol-coupling reaction. Macromol. Rapid Commun. 2006, 27, 2001-2006. [CrossRef]

30. Liu, C.; Cheng, H.M.; Zhao, H.; Yang, F.; Zhang, X. Surface modification of single-walled carbon nanotubes with polyethylene via in situ Ziegler-Natta polymerization. J. Appl. Polym. Sci. 2004, 92, 3697-3700.

31. Zhang, Y.; Li, Q.; Wang, W.; Guo, A.; Li, J.; Li, H. Efficient and robust reactions for polyethylene covalently grafted carbon nanotubes. Macromol. Chem. Phys. 2017, 218, 1600449. [CrossRef]

32. Baudot, C.; Volpe, M.V.; Kong, J.C.; Tan, C.M. Epoxy Functionalized Carbon Nanotubes and Methods of Forming the Same. U.S. Patent 299,082, 12 April 2009.

33. Díez-Pascual, A.M.; Naffakh, M. Grafting of an aminated poly(phenylene sulphide) derivative to functionalized single-walled carbon nanotubes. Carbon 2012, 50, 857-868. [CrossRef]

34. Wu, W.; Zhang, S.; Li, Y.; Li, J.; Liu, L.; Qin, Y.; Guo, Z.-X.; Dai, L.; Ye, C.; Zhu, D. PVK-modified single walled carbon nanotubes with effective photo induced electron transfer. Macromolecules 2003, 36, 6286-6288. [CrossRef]

35. Blake, R.; Gun'ko, Y.K.; Coleman, J.; Cadek, M.; Fonseca, A.; Nagy, J.B.; Blau, W.J. A generic organometallic approach toward ultra-strong carbon nanotube polymer composites. J. Am. Chem. Soc. 2004, 126, 10226-10227. [CrossRef]

36. Qin, S.; Qin, D.; Ford, W.T.; Resasco, D.E.; Herrera, J.E. Functionalization of single-walled carbon nanotubes with polystyrene via grafting to and grafting from methods. Macromolecules 2004, 37, 752-757. [CrossRef]

37. Li, H.; Cheng, F.; Duft, A.M.; Adronov, A. Functionalization of single walled carbon nanotubes with well-defined polystyrene by "click" coupling. J. Am. Chem. Soc. 2005, 127, 14518-14524. [CrossRef]

38. Li, Z.; Dong, Y.; Haussler, M.; Lam, J.W.Y.; Dong, Y.; Wu, L. Synthesis of, light emission from, and optical power limiting in soluble single-walled carbon nanotubes functionalized by disubstituted polyacetylenes. J. Phys. Chem. B 2006, 110, 2302-2309. [CrossRef]

39. Lin, Y.; Zhou, B.; Fernando, K.A.S.; Liu, P.; Allard, L.F.; Sun, Y.P. Polymeric carbon nanocomposites from carbon nanotubes functionalized with matrix polymer. Macromolecules 2003, 36, 7199-7204. [CrossRef]

40. Zhao, B.; Hu, H.; Yu, A.; Perea, D.; Haddon, R.C. Synthesis and characterization of water soluble single-walled carbon nanotube graft copolymers. J. Am. Chem. Soc. 2005, 127, 8197-8203. [CrossRef] [PubMed]

41. Diez-Pascual, A.M.; Martinez, G.; Gonzalez-Dominguez, J.M.; Martinez, T.; Gomez-Faou, M.A. Grafting of a hydroxylated PEEK derivative to the surface of single-walled carbon nanotubes. J. Mater. Chem. 2010, 20, 8285-8296. [CrossRef]

42. Wang, T.Z.; Tseng, C.G. Polymeric carbon nanocomposites from multiwalled carbon nanotubes functionalized with segmented polyurethane. J. Appl. Polym. Sci. 2007, 105, 1642-1650. [CrossRef]

43. Zhang, Q.; Huang, S.; Yu, F.; Fu, H.; Li, L.; Yan, G. Synthesis and characterization of ester bond-containing polyethyleneimine functionalized carbon nanotubes. IOP Conf. Ser. Mater. Sci. Eng. 2019, 472, 012002. [CrossRef]

44. Kitano, H.; Tachimoto, K.; Anraku, Y.J. Functionalization of single-walled carbon nanotube by the covalent modification with polymer chains. J. Colloid Interfaces Sci. 2007, 306, 28-33. [CrossRef] [PubMed]

45. Wie, J.; Kim, J. Thermal conductivity enhancement derived from poly(methyl methacrylate)-grafted carbon nanotubes in poly(methyl methacrylate)/polystyrene blends. Polymers 2019, 11, 1347. [CrossRef]

46. Lin, Y.; Rao, A.M.; Sadanadan, B.; Kenik, E.A.; Sun, Y.P. Functionalizing multiple-walled carbon nanotubes with aminopolymers. J. Phys. Chem. B 2002, 106, 1294-1298. [CrossRef]

47. Jung, Y.C.; Sahoo, N.G.; Cho, J.W. Polymeric nanocomposites of polyurethane block copolymers and functionalized multi-walled carbon nanotubes as crosslinkers. Macromol. Rapid. Commun. 2006, 27, 126-131. [CrossRef]

48. Wu, H.L.; Yang, Y.T.; Ma, C.C.M.; Kuan, H.C. Molecular mobility of freeradical-functionalized carbon-nanotube/siloxane/poly(urea urethane) nanocomposites. J. Polym. Sci. Part A Polym. Chem. 2005, 43, 6084-6094. [CrossRef]

49. Koshio, A.; Yudasaka, A.M.; Zhang, M.; Ijima, S. A simple way to chemically react single-wall carbon nanotubes with organic materials using ultrasonication. Nano Lett. 2001, 1, 361-363. [CrossRef]

50. Kong, H.; Gao, C.; Yan, D. Controlled functionalization of multiwalled carbon nanotubes by in situ atom transfer radical polymerization. J. Am. Chem. Soc. 2004, 126, 412-413. [CrossRef]

51. Wang, Y.; Tian, C.; Jiang, H.; Zhang, L.; Zhu, X. Surface modification of carbon nanotubes by using iron-mediated activators generated by electron transfer for atom transfer radical polymerization. RSC Adv. 2018, 8, 11150-11156. [CrossRef] 
52. Yao, Z.; Braidy, N.; Botton, G.A.; Adronov, A. Polymerization from the surface of single-walled carbon nanotubes-preparation and characterization of nanocomposites. J. Am. Chem. Soc. 2003, 125, 16015-16024. [CrossRef]

53. Baskaran, D.; Dunlap, J.R.; Mays, J.W.; Bratcher, M.S. Grafting efficiency of hydroxy-terminated poly(methyl methacrylate) with multiwalled carbon nanotubes. Macromol. Rapid. Commun. 2005, 26, 481-486. [CrossRef]

54. Liu, M.; Yang, Y.; Zhu, T.; Liu, Z. A general approach to chemical modification of single-walled carbon nanotubes with peroxy organic acids and its application in polymer grafting. J. Phys. Chem. C 2007, 111, 2379-2385. [CrossRef]

55. Cui, J.; Wang, W.P.; You, Y.Z.; Liu, C.; Wang, P. Functionalization of multiwalled carbon nanotubes by reversible addition fragmentation chain-transfer polymerization. Polymer 2004, 45, 8717-8721. [CrossRef]

56. Hong, C.Y.; You, Y.Z.; Pan, C.Y. Synthesis of water-soluble multiwalled carbon nanotubes with grafted temperature-responsive shells by surface RAFT polymerization. Chem. Mater. 2005, 17, 2247-2254. [CrossRef]

57. Xu, G.; Wang, Y.; Pang, W.; Wu, W.-T.; Zhu, Q.; Wang, P. Fabrication of multiwalled carbon nanotubes with polymer shells through surface RAFT polymerization. Polym. Int. 2007, 56, 847-852. [CrossRef]

58. Qu, L.; Veca, L.M.; Lin, Y.; Kitaygorodskiy, A.; Chen, B.; McCall, A.M.; Connell, J.W.; Sun, Y.-P. Soluble nylon-functionalized carbon nanotubes from anionic ring opening polymerization from nanotube surface. Macromolecules 2005, 38, 10328-10331. [CrossRef]

59. Yang, M.; Gao, Y.; Li, H.; Adronov, A. Functionalization of multiwalled carbon nanotubes with polyamide 6 by anionic ringopening polymerization. Carbon 2007, 45, 2327-2333. [CrossRef]

60. Russell, K.E. Free radical graft polymerization and copolymerization at higher temperatures. Progress Polym. Sci. 2002, 27, 1007-1038. [CrossRef]

61. Shaffer, M.S.P.; Koziol, K. Polystyrene grafted multi-walled carbon nanotubes. Chem. Commun. 2002, 2002, 2074-2075. [CrossRef]

62. Yang, Y.; Xie, X.; Wu, J.; Mai, Y.W. Synthesis and self-assembly of polystyrene-grafted multiwalled carbon nanotubes with a hairy-rod nanostructure. J. Polym. Sci. A Polym. Chem. 2006, 44, 3869-3881. [CrossRef]

63. Qin, S.; Qin, D.; Ford, W.T.; Herrera, J.E.; Resasco, D.E.; Bachilo, S.M.; Weisman, R.B. Solubilization and purification of single-wall carbon nanotubes in water by in situ radical polymerization of sodium 4-styrenesulfonate. Macromolecules 2004, 37, 3965-3967. [CrossRef]

64. Yue, B.; Wang, Y.; Huang, C.Y.; Pfeffer, R.; Iqbal, Z. Polymeric nanocomposites of functionalized carbon nanotubes synthesized in supercritical $\mathrm{CO}_{2}$. J. Nanosci. Nanotechnol. 2007, 7, 994-1000. [CrossRef] [PubMed]

65. Soleyman, R.; Hirbod, S.; Adeli, M. Advances in the biomedical application of polymer-functionalized carbon nanotubes. Biomater. Sci. 2015, 3, 695-711. [CrossRef] [PubMed]

66. Zhang, B.; Chen, Q.; Tang, H.; Xie, Q.; Ma, M.; Tan, L.; Zhang, Y.; Yao, S. Characterization of and biomolecule immobilization on the biocompatible multi-walled carbon nanotubes generated by functionalization with polyamidoamine dendrimers. Colloids Surf. B 2010, 80, 18-25. [CrossRef] [PubMed]

67. El-Said, W.A.; Abdelshakour, M.; Choi, J.-H.; Choi, J.-W. Application of conducting polymer nanostructures to electrochemical biosensors. Molecules 2020, 25, 307. [CrossRef]

68. Choi, S.-H.; Chung, D.-J.; Kwen, H.-D. Fabrication of biosensors using vinyl polymer-grafted carbon nanotubes. In New Perspectives in Biosensors Technology and Applications; Intech Open: London, UK, 2011.

69. Sianipar, M.; Kim, S.H.; Khoiruddin, K.; Iskandar, F.; Wenten, I.G. Functionalized carbon nanotube (CNT) membrane: Progress and challenges. RSC Adv. 2017, 7, 51175-51198. [CrossRef]

70. Gu, J.; Xiao, P.; Chen, J.; Zhang, J.; Huang, Y.; Chen, T. Janus polymer/carbon nanotube hybrid membranes for oil/water separation. ACS Appl. Mater. Interfaces 2014, 6, 16204-16209. [CrossRef] [PubMed]

71. Soyekwo, F.; Zhang, Q.; Chen, M.; Qu, Y.; Gao, R.; Lv, R.; Zhu, A.; Liu, Q.L. Metal in-situ surface functionalization of polymergrafted-carbon nanotube composite membranes for fast efficient nanofiltration. J. Mater. Chem. A. 2017, 5, 583-592. [CrossRef]

72. Hsiao, M.C.; Liao, S.H.; Lin, Y.F.; Weng, C.C.; Tsai, H.M.; Ma, C.C.M.; Lee, S.H.; Yen, M.Y.; Liu, P.I. Polypropylene-grafted multi-walled carbon nanotube reinforced polypropylene composite bipolar plates in polymer electrolyte membrane fuel cells. Energy Environ. Sci. 2011, 4, 543-550. [CrossRef]

73. Han, H.; Kim, D.Y.; Jo, S.M.; Jang, S.Y. Water-soluble polyelectrolyte-grafted multiwalled carbon nanotube thin films for efficient counter electrode of dye-sensitized solar cells. ACS Nano 2010, 4, 3503-3509. [CrossRef] [PubMed]

74. Abbasi, H.; Antunes, M.; Velasco, J.I. Recent advances in carbon-based polymer nanocomposites for electromagnetic interference shielding. Prog. Mater. Sci. 2019, 103, 319-373. [CrossRef]

75. Diez-Pascual, A.M.; Martínez, G.; Martinez, M.T.; Gómez, M.A. Novel nanocomposites reinforced with hydroxylated poly(ether ether ketone)-grafted carbon nanotubes. J. Mater. Chem. 2010, 20, 8247-8256. [CrossRef]

76. Hayashida, K.; Matsuoka, Y. Electromagnetic interference shielding properties of polymer-grafted carbon nanotube composites with high electrical resistance. Carbon 2015, 85, 363-371. [CrossRef]

77. Poothanari, M.A.; Abraham, J.; Kalarikkal, N.; Thomas, S. Excellent electromagnetic interference shielding and high electrical conductivity of compatibilized polycarbonate/ polypropylene carbon nanotube blend nanocomposites. Ind. Eng. Chem. Res. 2018, 57, 4287-4297. [CrossRef] 